Check for updates

Cite this: RSC Adv., 2018, 8, 33798

\title{
Investigation of dynamical properties of methane in slit-like quartz pores using molecular simulation
}

\author{
Lilong Yang, (D) a Xiang Zhou, (D) ${ }^{a}$ Kewei Zhang, ${ }^{\text {b }}$ Fanhua Zeng (D) *a \\ and Zhouhua Wang ${ }^{c}$
}

The dynamical properties of adsorption media confined in micropores play an important role in the adsorptive separation of fluids. However, a problem is that it is difficult to directly use approaches based on experimental measurements. Molecular simulation has been an effective tool for investigating the diffusion of fluids on the microscale in recent years. In this work, the diffusion properties of methane in quartz were mainly investigated from a microscale viewpoint using MD (molecular dynamics) methods, and this paper primarily discusses the influence of parameters such as pressure, temperature, pore size and water content on the diffusion and thermodynamic parameters of methane in slit-like quartz pores. The results demonstrate that the transport ability of quartz pores decreases with an increase in pressure in pores of a fixed size at a certain temperature and increases with an increase in pore size or temperature at a fixed pressure, which is related to changes in the interaction between methane molecules and quartz. In the pressure range used in the simulation, the average isosteric heat of adsorption of methane increases with an increase in pressure and is in the range of 6.52$10.794 \mathrm{~kJ} \mathrm{~mol}^{-1}$. Therefore, the gas adsorption behavior is classed as physical adsorption because the heat of adsorption is significantly lower than the minimum heat of gas adsorption for chemisorption. The increase in the total adsorption entropy is caused by an increase in temperature due to an increase in internal energy, which brings about a reduction in the interactions between gas molecules and walls of quartz. However, with an increase in pore size the total adsorption entropy increases, for which an explanation may be that in pores of a larger size methane molecules are adsorbed at higher-energy sites and generate a higher isosteric heat, which causes a reduction in interactions between the adsorbate and adsorbent. Regarding the influence of different water contents on the diffusion of methane, it was demonstrated that with an increase in moisture the mobility of methane molecules initially increases and then decreases, which is related to the distance between gas molecules.

Received 9th August 2018 Accepted 19th September 2018

DOI: $10.1039 / \mathrm{c} 8 \mathrm{ra06678g}$

rsc.li/rsc-advances expected to account for $70 \%$ of the US natural gas production in 2040, and shale resource developments in China are expected to account for nearly $50 \%$ of domestic natural gas production by 2040 to meet the demand for natural gas consumption. ${ }^{1}$ Thus, shale gas will be one of the most important sources of energy in the near future. As we know, shale gas reservoirs mainly contain free gas, dissolved gas, and adsorbed gas. Curtis (2002) stated that the maximum amount of adsorbed gas is up to $85 \%$ in American shale reservoirs. ${ }^{2}$ Therefore, it is essential for researchers to study the adsorption characteristics of methane to find advanced recovery techniques for the improvement of shale and tight oil resources to meet the growing demand for energy.

In order to more accurately determine the petrophysical properties of rock samples from shale gas reservoirs, X-ray diffraction (XRD) is used to analyze the rock mineralogy for the evaluation of shale. It was found that there was an abundant amount of quartz minerals in some shale samples. ${ }^{3}$ Yingjie et al. (2015) conducted geochemical tests to investigate the effects of composition on the capacity of the gas reservoir in the Qaidam 
Basin, China, and suggested that the quartz content of the shale is up to $87 \%{ }^{4}$ An investigation of the pore structure and fracture characteristics of the organic-rich Yanchang Formation shale in the Ordos Basin demonstrated that the quartz content of the shale ranged from $17.10 \%$ to $72.33 \%$ and represented the main component of the shale. ${ }^{5}$ Some researchers (Ross and Marc Bustin) investigated the shale composition of Western Canadian shale gas reservoirs from different geologic periods and suggested that the average content of quartz mineral phases is over $44 \%{ }^{6}$ Therefore, it is meaningful for researchers to observe the characteristics of the gas adsorption capacity of quartz in shale gas reservoirs. Recently, some scholars have applied experimental and theoretical methods to study the adsorption behavior of methane in nanoporous pure quartz. Xiong et al. (2017) observed the influence of different pore sizes on the methane adsorption capacity of quartz pores using experimental methods. ${ }^{7}$ Ji et al. (2013) and Liang et al. (2016) observed the impact of environmental factors that included temperature and pressure on the adsorption behavior of $\mathrm{CH}_{4}$ in quartz. ${ }^{8,9}$ Xiong et al. (2016) used molecular simulation to investigate the impact of environmental factors on the $\mathrm{CH}_{4}$ adsorption ability of quartz pores on the microscale. ${ }^{10}$ However, most researchers did not study in greater depth to investigate the dynamical properties that reflect the internal features of microscopic systems in quartz pores.

An observation of the impact of different factors on the dynamical properties of adsorption media could provide a fundamental understanding of the internal behavior of fluids in adsorbents for researchers. Cracknell et al. (1995) investigated transport diffusivity in slit-shaped pores of different sizes using a computerized molecular dynamics (MD) method, which showed that the self-diffusion of methane was a function of its concentration for different pore sizes. ${ }^{11}$ Titiloye and Skipper (2001) studied the distribution and mobility of methane particles in the interlayers of a sodium montmorillonite clay hydrate using a molecular simulation, which suggested that interlayer mobility has a strong relationship with moisture and burial depth. ${ }^{12}$ Cao and Wu (2004) studied the influences of different temperatures and pressures under subcritical and supercritical conditions on the behavior of the diffusion coefficient of methane in single-walled carbon nanotubes (SWNTs) by combining GCMC (grand canonical Monte Carlo) and ideal MD methods, which suggested that kinetic energy and intermolecular interactions play a critical part in the mobility of methane molecules below a supercritical temperature. ${ }^{13}$ Yang and Zhang (2005) investigated the structure and diffusion behaviour of $\mathrm{CO}_{2}$ in different clay-like slit pores via a classical MD method, which demonstrated the distribution of the inner molecular layer and the relationship of the diffusion coefficient of $\mathrm{CO}_{2}$ with various slit pores. ${ }^{14}$ Fathi and Akkutlu (2009) studied the influence of surface diffusion on the macroscale transport of gas in a lowpermeability formation and found that surface diffusion is an important factor that affects the eventual recovery of gas. ${ }^{15}$ Bhatia and Nicholson (2012) observed the influences of different methane densities on the dynamical behavior of methane in silica nanopores at different pore sizes and temperatures using an MD simulation method..$^{16}$ Li et al. (2013) investigated the density profile and divergent behavior of an RTIL (room-temperature ionic liquid) close to the surface of silica and carbon using a molecular simulation, which revealed the interfacial potential profile and the confinement of temperature-dependent diffusion within silica or carbon pores. ${ }^{17}$ Sharma, Namsani, and Singh (2015) studied the influences of different pore sizes and pressures on the dynamical behavior of ethane and methane in montmorillonite nanopores and suggested that the diffusion coefficient of methane is lower than that of ethane at a lower pressure. ${ }^{18}$ Huang et al. (2014) and Sui and Yao (2016) observed the influences of pressure, slit pore size, temperature, and concentration on the diffusion behavior of different fluids in slit-like pores using a molecular dynamics method. ${ }^{19,20}$ According to the above review, these studies suggest that it is effective to use molecular simulation methods to study the dynamical properties of a flue gas on an adsorbent. Furthermore, not enough reports provide specific information on dynamical properties on pure minerals.

This study mainly used MD simulations based on equilibrium configurations, which can be determined from a GCMC simulation, to observe the dynamical behavior of a gas in a quartz pore. Firstly, the structures of nanopores were built using a molecular simulation. On the basis of the first step, the dynamical properties in quartz pores were investigated to determine how factors including the pressure, temperature, pore size, and water content affect the diffusion behaviour and thermodynamic parameters in quartz for the purpose of providing a theoretical basis and instructional guidance for enhancing the production of shale gas in shale gas reservoirs.

\section{Establishment and validation of the model}

\subsection{Models}

Methane exists mainly in an adsorbed state in micropores in sandstone, and diffusion is an important way to produce gas in micropores. Therefore, it is important to study the microscale mechanism and diffusion of $\mathrm{CH}_{4}$ in slit-like quartz pores. In this paper, using the Materials Studio software package for the structure of the alpha quartz unit cell $(4.91 \AA$ e $4.91 \AA \times 5.402$ $\AA)$ enabled the construction of an adsorbent structure. In addition, a model of the $\mathrm{CH}_{4} / \mathrm{H}_{2} \mathrm{O}$ fluid was established using the Materials Studio (MS) software package. A simulation of the quartz unit cell was set up in a square box with cyclicity in the $x$ and $y$ directions on the basis of the unit cell of quartz crystals. The quartz model comprised a $6 a \times 5 b \times 5 z$ supercell structure in the $x, y$, and $z$ directions. Therefore, the range of the model of the quartz supercell structure can be determined $(x=2.946 \mathrm{~nm}, y=2.455 \mathrm{~nm}$ and $z=2.521 \mathrm{~nm})$, and $S$, which is the area of the crystal surface in the porous structure, is 6.261 $\times 10^{-18} \mathrm{~m}^{2}$. In order to calculate the different pore diameters of quartz in the model of the supercell structure, a void was added in the $z$ direction according to the simulation unit cell. The pore height $(H)$ was determined by simulating a vacuum, and we used different lengths in combination with $H$ to obtain different pore sizes (such as $1 \mathrm{~nm}, 2 \mathrm{~nm}, 2.5 \mathrm{~nm}, 4 \mathrm{~nm}$, and 6 
$\mathrm{nm}$ ). Different schematic representations of the vacuum and fluid models are presented in Fig. 1.

\subsection{Calculation method and scheme design}

In this simulation, we used the Condensed-Phase Optimized Molecular Potential for Atomistic Simulation Studies (COMPASS) field, which was mentioned by previous researchers. ${ }^{\text {21,22 }}$ This force field includes a covalent-bond model, an ion model, a quasi-ion model, and a metal model that can describe different molecular systems. The covalent-bond model is applicable to all organic molecules and inorganic covalently bonded molecular systems, including small molecules and macromolecules. The force field is the same as those used in CFF-type force fields. The function forms consist of two parts: (a) valence terms and (b) non-bonding interactions. The valence terms include diagonal and off-diagonal cross-coupling terms that involve the bond stretching energy $E_{b}$, bond angle bending energy $E_{\theta}$, bond torsion energy $E_{\varphi}$, bond out-of-plane angle bending energy $E_{\chi}$ and cross-coupling terms energy $E_{\text {cross: }}$ :

$$
\begin{gathered}
E_{\text {bond }}=E_{b}+E_{\theta}+E_{\varphi}+E_{\chi}+E_{\text {cross }} \\
E_{b}=\sum_{b}\left[K_{2}\left(b-b_{0}\right)^{2}+K_{3}\left(b-b_{0}\right)^{3}+K_{4}\left(b-b_{0}\right)^{4}\right] \\
E_{\theta}=\sum_{\theta}\left[K_{2}\left(\theta-\theta_{0}\right)^{2}+K_{3}\left(\theta-\theta_{0}\right)^{3}+K_{4}\left(\theta-\theta_{0}\right)^{4}\right]
\end{gathered}
$$

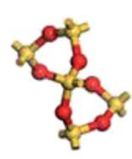

(a) Unit $\alpha$-quartz cell (oxygerO ; Osilicon)

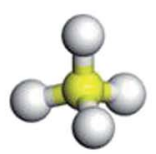

(c) $\mathrm{CH}_{4}$ fluid model

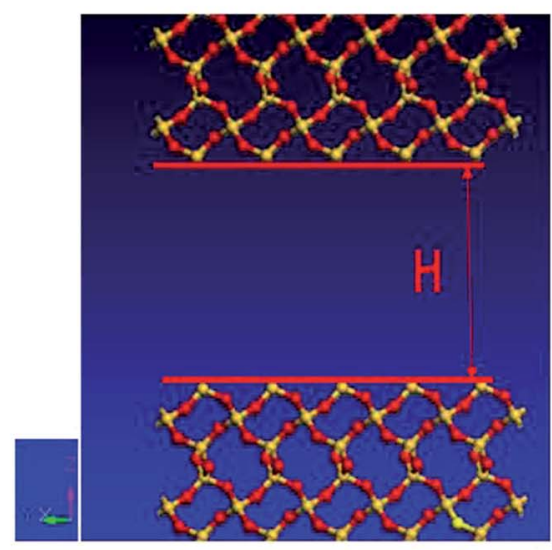

(d) Structure of slit-like quartz pores

Fig. 1 Fluid models and structure of slit-like quartz pores.

$$
\begin{aligned}
& E_{\varphi}=\sum_{\varphi} {\left[K_{1}(1-\cos \varphi)+K_{2}(1-\cos 2 \varphi)+K_{3}(1-\cos 3 \varphi)\right] } \\
& E_{\chi}=\sum_{\chi} K_{2} \chi^{2} \\
& E_{\mathrm{cross}}=\sum_{b b^{\prime}} K\left(b-b_{0}\right)\left(b-b_{0}^{\prime}\right)+\sum_{b, \theta} K\left(b-b_{0}\right)\left(\theta-\theta_{0}\right) \\
&+\sum_{b, \varphi}\left(b-b_{0}\right)\left(K_{1} \cos \varphi+K_{2} \cos 2 \varphi+K_{3} \cos 3 \varphi\right) \\
&+\sum_{b^{\prime}, \varphi}\left(b^{\prime}-b_{0}\right)\left(K_{1} \cos \varphi+K_{2} \cos 2 \varphi+K_{3} \cos 3 \varphi\right) \\
&+\sum_{\theta, \varphi}\left(\theta-\theta_{0}^{\prime}\right)\left(K_{1} \cos \varphi+K_{2} \cos 2 \varphi+K_{3} \cos 3 \varphi\right) \\
&+\sum_{\theta^{\prime}, \theta}\left(\theta^{\prime}-\theta\right)\left(\theta-\theta_{0}\right)+\sum_{\theta, \theta^{\prime}, \varphi} K\left(\theta-\theta_{0}\right)\left(\theta-\theta_{0}^{\prime}\right) \cos \varphi
\end{aligned}
$$

For non-bonding interactions, the van der Waals (vdW) term energy $E_{i j}$ was included, which comprises the Lennard-Jones 9-6 function $^{23}$ and the electrostatic interaction energy $E_{\text {elec: }}$ :

$$
\begin{gathered}
E_{i j}=\sum_{i j} \varepsilon_{i j}\left[2\left(\frac{r_{i j}^{0}}{r_{i j}}\right)^{9}-3\left(\frac{r_{i j}^{0}}{r_{i j}}\right)^{6}\right] \\
E_{\mathrm{elec}}=\sum_{i, j} \frac{q_{i} q_{j}}{r_{i j}}
\end{gathered}
$$

For similar atom pairs, the Lennard-Jones 9-6 parameters are given, whereas for dissimilar atom pairs, a $6^{\text {th }}$ order combination law is used to determine the values of the off-diagonal parameters: ${ }^{24}$

$$
\begin{gathered}
r_{i j}^{0}=\left(\frac{\left(r_{i}^{0}\right)+\left(r_{j}^{0}\right)^{6}}{2}\right)^{\frac{1}{6}} \\
\varepsilon_{i, j}=2 \sqrt{\varepsilon_{i} \varepsilon_{j}}\left(\frac{\left(r_{i}^{0}\right)^{3}\left(r_{j}^{0}\right)^{3}}{\left(r_{i}^{0}\right)^{6}\left(r_{j}^{0}\right)^{6}}\right)
\end{gathered}
$$

In the COMPASS field, partial atomic charges are used to represent electrostatic interactions. In the force field, the bond increment $\delta_{i j}$ is used to represent the charge separation between two valence-bonded atoms, and $i$ and $j$ are used as atomic parameters. For atom $i$, the partial charge is the sum of all charge bond increments $\delta_{i j}::^{24}$

$$
q_{i}=\sum_{j} \delta_{i j}
$$

where $j$ represents all atoms that are valence-bonded to atom $i$.

In the simulation, MD methods based on the GCMC method were used. The GCMC method was employed to fill the pores 
with methane molecules and was launched using the sorption module in the MS software package. In this work, it is worth mentioning that the grand canonical ensemble refers to the chemical potential of the system in the process of the simulation. In the process of a GCMC simulation, the acceptance probability of three kinds of particles in the system is a function of the chemical potential. The relationship between the chemical potential and the fugacity is as follows: ${ }^{25}$

$$
\mu=\mu^{\prime}(g) R T \ln \frac{f}{p^{\prime}}
$$

where $\mu^{\prime}(g)$ is the chemical potential of the gas in the standard state $\left(\mathrm{J} \mathrm{mol}^{-1}\right), R$ is the gas constant $\left(\mathrm{J} \mathrm{mol}^{-1} \mathrm{~K}^{-1}\right)$, and $p^{\prime}$ is the pressure in the standard state $(\mathrm{Pa})$. In this study, the simulated pressure was up to $30 \mathrm{MPa}$, and each simulation was carried out at 15 fixed pressure values. In addition, Metropolis was used as the output sampling method. In the specific calculation processes, each simulation used a maximum of $3.2 \times 10^{6}$ load steps, of which $1.6 \times 10^{6}$ were balance steps and $1.6 \times 10^{6}$ were process steps that could be chosen to analyze the density distributions and diffusion behavior of methane. Moreover, the work employed an atomic-interaction-based approach to calculate van der Waals forces within a cutoff distance of $1.2 \mathrm{~nm}$, and coulombic force interactions were determined via the Ewald\&Group method. In chemical thermodynamics, the fugacity of a real gas is a valid partial pressure that is used instead of the mechanical partial pressure in a precise calculation of the chemical equilibrium constant. For an ideal gas, the pressure is equal to the fugacity. In this study, we used the Peng-Robinson equation of state to determine the density of the gas phase and fugacity coefficient. ${ }^{26}$

To study the different factors that influence the transport properties and density profiles of methane molecules in slit-like pores, a molecular dynamics method needed to be employed in this work. In the MD simulations, the simulated pressure was up to $30 \mathrm{MPa}$, and each simulation used a certain pressure value corresponding to a temperature value, which was carried out using the Forcite module in the MS software package. In the MD simulations, the COMPASS force field was used. The simulation used the Ewald\&Group method to calculate the coulombic force interactions, and the van der Waals forces were calculated by an atomic-interaction-based method. Each MD simulation was carried out using an $N V T$ ensemble (the atom number $N$, volume $V$, and temperature $T$ stay the same in the system) with a dynamic time of $1 \mathrm{~ns}$ and a time step of $1 \mathrm{~ns}$, which included a structural equilibration time of $100 \mathrm{ps}$ and a calculation time of $900 \mathrm{ps}$ for methane molecules. The Andersen thermostat was used to control the temperature. Finally, a molecular equilibrium configuration that was built up at intervals of 100 steps in each simulation process was obtained to calculate the dynamical behavior of methane and study the density distributions of methane.

In order to study the dynamical properties of methane molecules, this work mainly chose various factors, which included pressure, temperature, pore size, and water saturation, to study the transport ability and thermodynamic parameters of gas molecules in slit-like quartz pores. The simulation program included: (1) using different pressures, including $5 \mathrm{MPa}, 9 \mathrm{MPa}$, $13 \mathrm{MPa}, 17 \mathrm{MPa}, 21 \mathrm{MPa}$, and $30 \mathrm{MPa}$, to investigate the diffusion and heat of adsorption in slit-like quartz pores; (2) choosing different temperatures, including $30^{\circ} \mathrm{C}, 60^{\circ} \mathrm{C}, 90^{\circ} \mathrm{C}$, $100{ }^{\circ} \mathrm{C}$, and $120{ }^{\circ} \mathrm{C}$, to study the diffusion and adsorption entropy in pores; (3) choosing different pore sizes $(1 \mathrm{~nm}, 2 \mathrm{~nm}$, $3 \mathrm{~nm}, 4 \mathrm{~nm}, 6 \mathrm{~nm}$, and $8 \mathrm{~nm}$ ) at different pressures to simulate the adsorption entropy and diffusion of methane; and (4) using different water contents of $2 \%, 4 \%, 8 \%$ and $16 \%$ at various pressures to study the diffusion and average heat of adsorption of methane.

\subsection{Model validation}

To prove the feasibility of the molecular simulation method of studying gas adsorption in nanometre pores, this work chose different pore sizes, including $1 \mathrm{~nm}, 2 \mathrm{~nm}, 3 \mathrm{~nm}, 4 \mathrm{~nm}$, and $6 \mathrm{~nm}$, to determine the adsorption capacity for excess methane at $60^{\circ} \mathrm{C}$ in each simulation. Then, the conclusions were used for a comparison with an earlier study on organic and inorganic shale. Because the simulation temperature is above the critical temperature of the gas, the adsorption behaviour of the gas on quartz comprises supercritical adsorption. Therefore, Gibbs suggested a formula for the excess amount adsorbed via supercritical adsorption. The relevant equation ${ }^{27}$ is as follows:

$$
M_{\mathrm{ex}}=m_{\mathrm{ab}}-\rho_{\mathrm{g}} V_{\mathrm{ad}}
$$

where $M_{\mathrm{ex}}$ is the excess adsorbed amount $\left(\mathrm{g} \mathrm{cm}^{-3}\right), m_{\mathrm{ab}}$ is the actual content of the adsorbed gas $\left(\mathrm{g} \mathrm{cm}^{-3}\right), \rho_{\mathrm{g}}$ is the density of the bulk gas $\left(\mathrm{g} \mathrm{cm}^{-3}\right)$, which is established using the PengRobinson equation of state, ${ }^{8}$ and $V_{\text {ad }}$ is the volume of the adsorbed phase $\left(\mathrm{cm}^{3}\right)$. In this study, the total gas content could be determined from each simulation, but was not the actual content of the adsorbed gas. Hence, a conversion to the excess adsorbed amount is needed according to studies by other researchers: ${ }^{28}$

$$
M_{\mathrm{ex}}=N-\rho_{\mathrm{g}} V_{\mathrm{p}} / \mathrm{MS}
$$

where $N$ is the total amount of gas $\left(\mathrm{mol} \mathrm{m}^{-2}\right), V_{\mathrm{p}}$ is the free volume of gas $\left(\mathrm{g} \mathrm{cm}^{-3}\right), M$ is the molar mass of the gas $\left(\mathrm{g} \mathrm{mol}^{-1}\right)$, and $S$ is the surface area of the unit cell $\left(\mathrm{m}^{2}\right)$. Isotherms for the total adsorbed amount of methane are shown in Fig. 2. From the figure, it is evident that the total adsorbed amount increases with an increase in pressure and that an increase in the pore size increases the total adsorbed amount. Moreover, high pressure favors the adsorption of methane in pores of larger sizes. This trend coincides with results for the adsorption of methane molecules on kaolinite ${ }^{28}$ and in silica nanopores. ${ }^{29}$ In Fig. 3, we can see that the excess adsorbed amount increases with pressure until it reaches the maximum capacity for excess adsorption. Then, it decreases with pressure. In addition, in the figure it can be seen that the larger are the pores in quartz, the smaller is the adsorption capacity for excess methane of the mesopores. These results agree with those from previous studies. ${ }^{10,30-32}$ When the capacity for excess adsorption is at a maximum, there is a maximum pressure $\left(P_{\max }\right)$ for different 


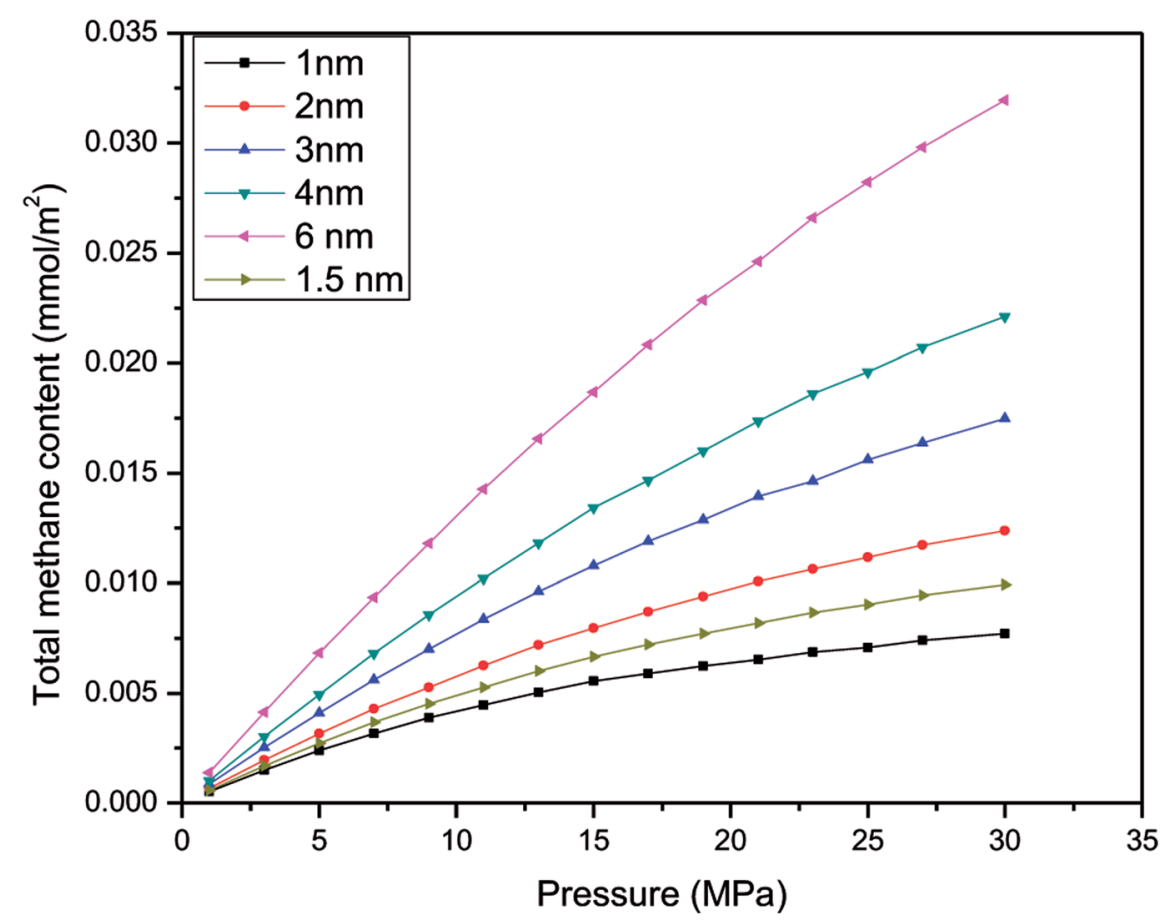

Fig. 2 Relationship between the excess adsorbed amount of $\mathrm{CH}_{4}$ and the pressure for various sizes of slit-like pores.

pore sizes. Table 1 shows the different maximum pressures for different pore sizes. The maximum capacity for excess adsorption under different pressures can be seen in Fig. 4, which displays the relationship between the maximum excess adsorbed amount of gas $\left(M_{\text {exc-max }}\right)$ and different sizes of slit-like quartz pores. Although the maximum pressures $\left(P_{\max }\right)$ are different from those in previous research because of the use of different parameters in this study, the conclusions are in accordance with previous works that showed that the maximum pressure for excess adsorption on quartz is between 10 and $19 \mathrm{MPa}$ on the basis of experiments. ${ }^{\mathbf{1 0 , 3 0 - 3 2}}$ In addition, we found that the maximum excess adsorbed amount in this work increases with an increase in the size of micropores, and a decrease in the maximum excess adsorbed amount is caused by an increase in the diameters of mesopores, which is shown in Fig. 4. In other words, the gas adsorption ability increases with

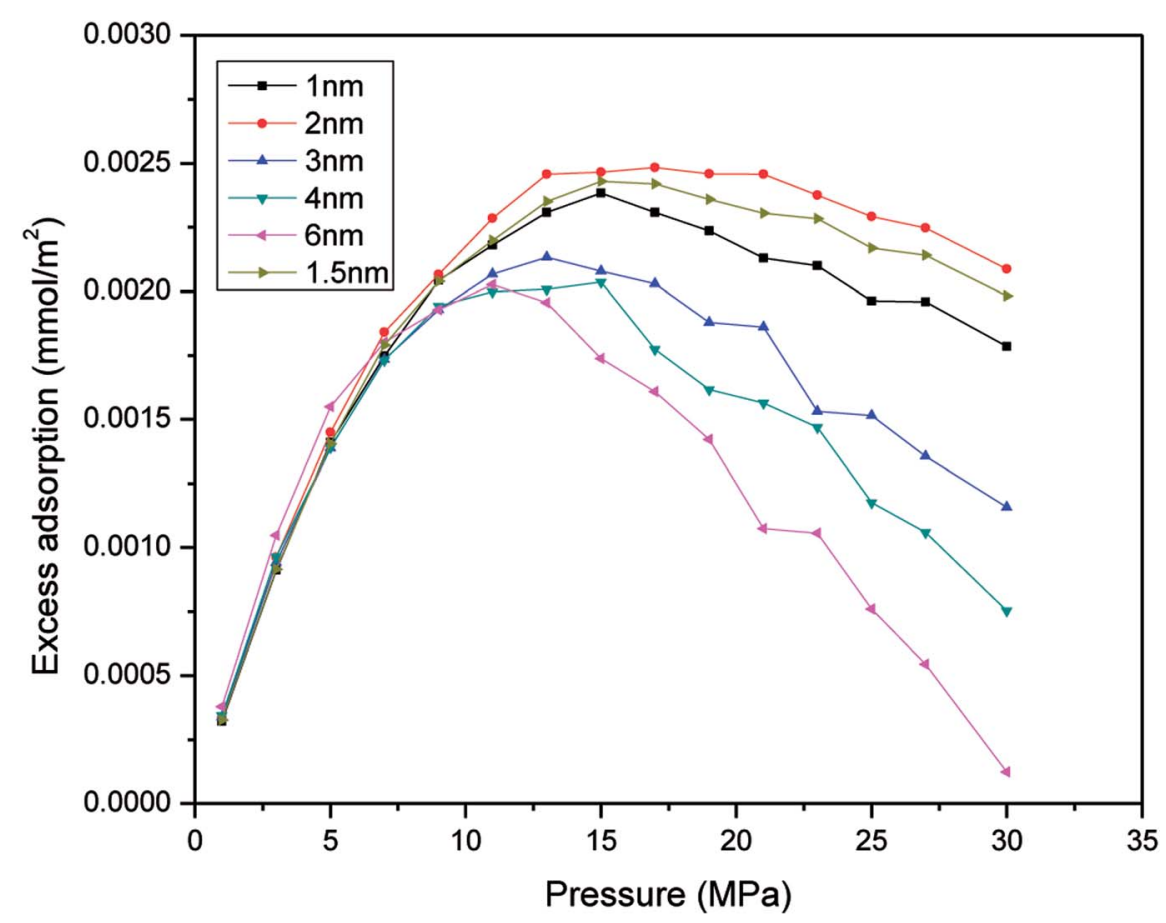

Fig. 3 Isotherms for the excess adsorbed amount of $\mathrm{CH}_{4}$ for different pore sizes. 
Table 1 Maximum pressures for different pore sizes in the simulation in this work

\begin{tabular}{ll}
\hline Pore size $(H) / \mathrm{nm}$ & $P_{\max } / \mathrm{MPa}$ (this work) \\
\hline 1 & 15 \\
1.5 & 17 \\
2 & 17 \\
3 & 13 \\
4 & 15 \\
6 & 11
\end{tabular}

an increase in the sizes of micropores and decreases when the diameters of mesopores are larger. This finding is similar to results in the previous literature. ${ }^{\mathbf{1 0}, 33}$ Therefore, this model is reasonable.

\section{Results and discussion}

\subsection{Variation in energy of the methane adsorption system in quartz}

Fig. 5 illustrates the relationship between the energy of the methane adsorption system and different pressures in slit-like quartz pores. In each simulation, we found that the valence terms do not make a contribution to the adsorption of methane in quartz. However, the total energy of the adsorption system is contributed by non-bonding interactions. In addition, we obtained the result that the van der Waals (vdW) term energy plays an important role in supplying the total energy to the adsorption system, and the electrostatic interaction energy is zero in non-bonding interactions. In other words, the electrostatic interaction energy does not make a contribution during the process of adsorption in each simulation, but the van der Waals (vdW) term energy makes a major contribution to the main energy in the adsorption system. Moreover, that contribution does not depend on the pressure and pore size, which indicates that the process of methane adsorption comprises a physical adsorption process in each simulation. When physical adsorption processes occur in an adsorption system, the system releases heat. Consequently, the energy of the system will decrease. From Fig. 5, we can draw the conclusion that the energy of the system will decrease as the pressure increases. Furthermore, the total energy of the adsorption system has no relationship with an increase in pore size.

\subsection{Properties of methane in a slit pore}

3.2.1 Impact of pressure. On the basis of the methane molecules adsorbed in slit-like pores that can be modeled using the GCMC simulation, we can also use this to study the dynamical properties of methane in slit-like quartz pores. The diffusion properties of methane are represented by the self-diffusion coefficient $(D)$, and the Einstein equation ${ }^{34}$ can be employed:

$$
D=\frac{1}{6} \lim _{t \rightarrow \infty} \frac{\mathrm{d}}{\mathrm{d} t} \sum_{i}^{n}\left\langle\left|r_{i}(t)-r_{i}(0)\right|^{2}\right\rangle
$$

where $\left|r_{i}(t)-r_{i}(0)\right|^{2}$ is the mean square displacement along the plane of the pore, $r_{i}(t)$ is the position of atom $i$ at time $t$, and $r_{i}(0)$ is the initial position of atom $i$. The diffusion coefficient of methane can be calculated for different pressures. The relationship between the diffusion coefficient of methane and the pressure is illustrated in Fig. 6. From the figure, we can see that a rise in pressure causes a decline in the diffusion coefficient of

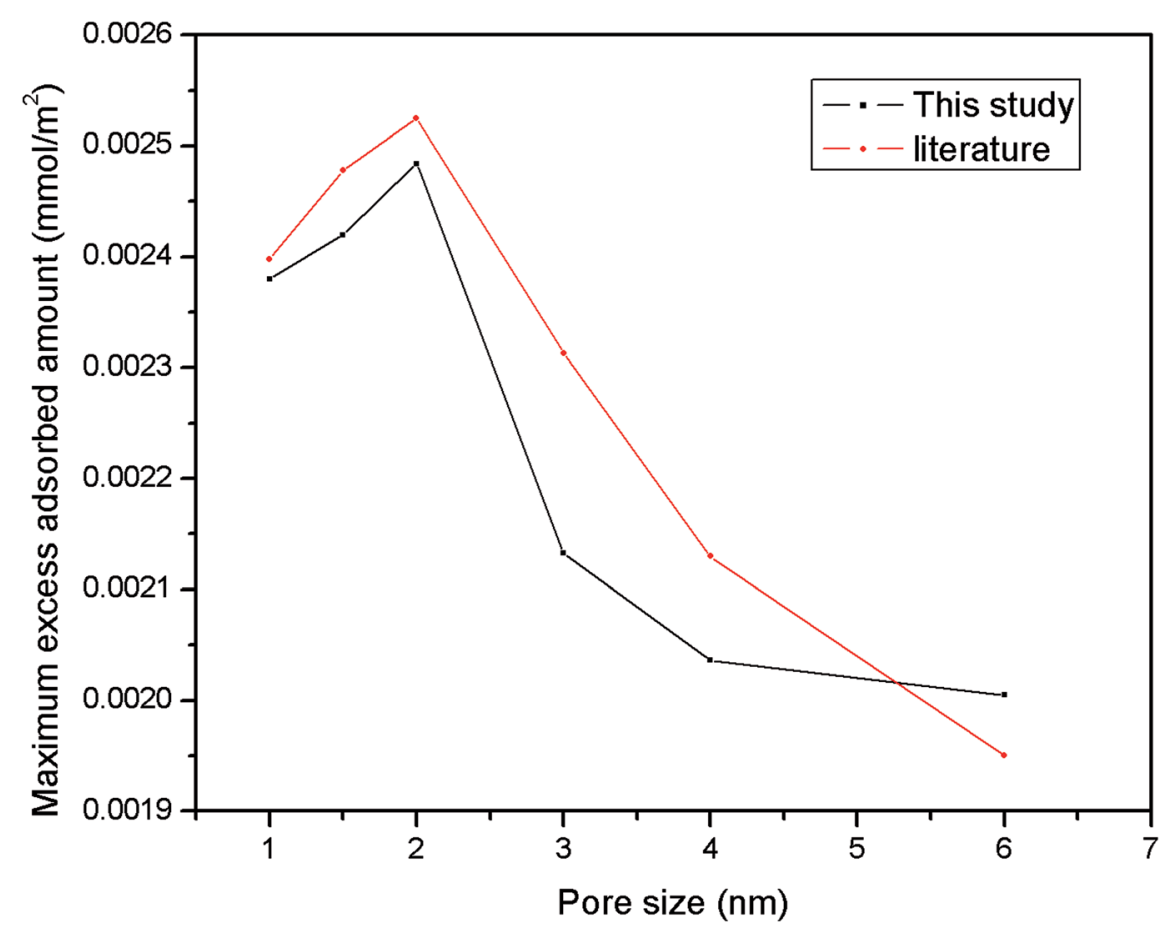

Fig. 4 Comparison of the maximum excess adsorbed amount in this work with literature results from previous papers. ${ }^{10,32}$ 


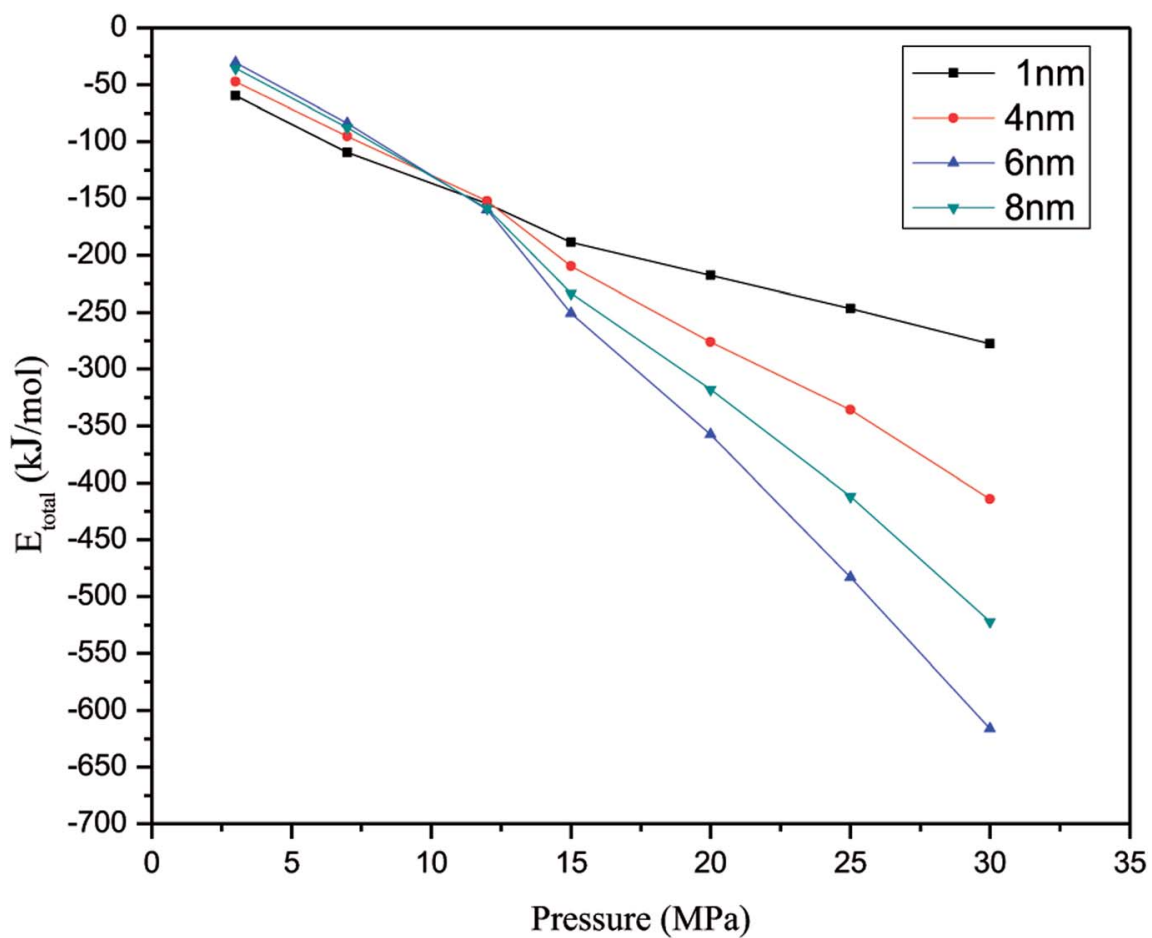

Fig. 5 Change in $E_{\text {total }}$ of the adsorption system at various pressures ( $E_{\text {total }}$ represents the total energy in the system).

methane, because the interaction forces between methane and the walls of the pores increase with an increase in pressure, which results in an increase in the resistance of the gas. This result is in accordance with earlier reports on single-walled carbon nanotubes ${ }^{13}$ and inorganic nanopores. ${ }^{18}$ Moreover, it can be seen in Fig. 6 that the self-diffusion coefficient of methane at different pressures is of the order of $10^{-8} \mathrm{~m}^{2} \mathrm{~s}^{-1}$, which is the same order as that determined for methane under supercritical conditions in single-walled carbon nanotubes by some researchers. ${ }^{13}$

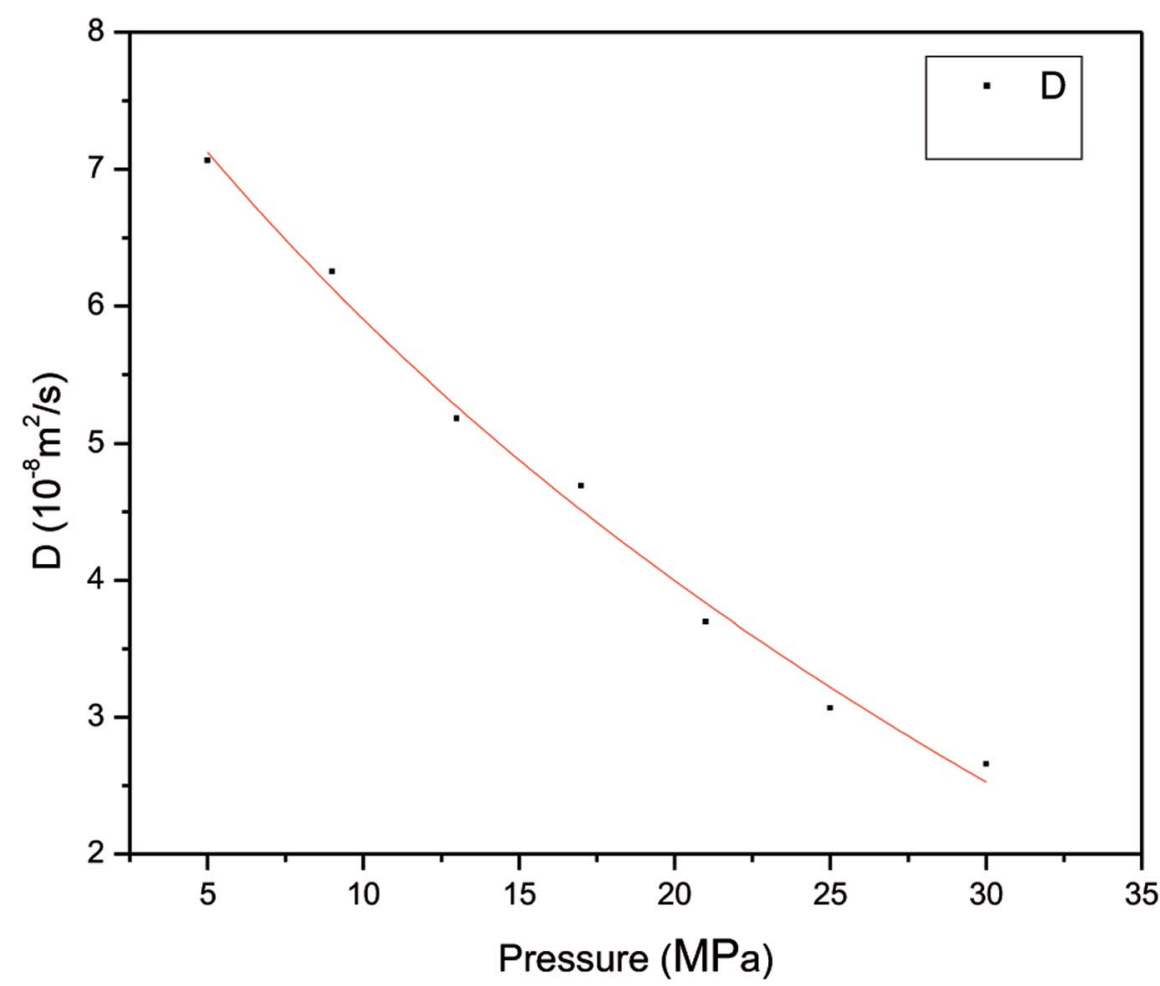

Fig. 6 Relationship between diffusion coefficient of methane and pressure in pores with a size of $1 \mathrm{~nm}$ at $60^{\circ} \mathrm{C}$. 


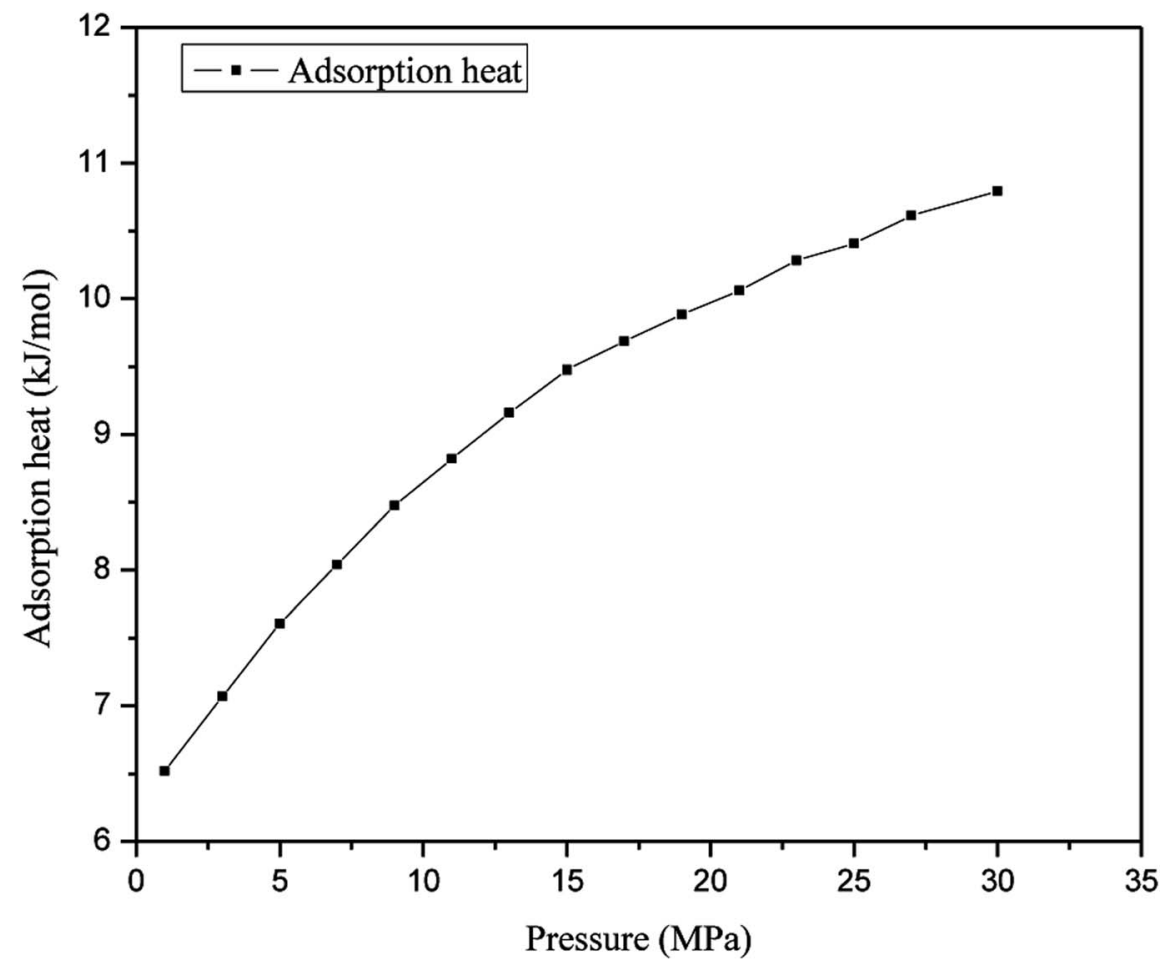

Fig. 7 Correlation between heat of adsorption and pressure.

The heat of adsorption is an important thermodynamic parameter for the adsorption of gas molecules on an adsorbent. ${ }^{35}$ The heat of adsorption of methane in nanopores at different pressures is illustrated in Fig. 7, which shows that the heat of adsorption of the gas increases with an increase in pressure. In this simulation, the heat of adsorption of methane has a minimum value of $6.52 \mathrm{~kJ} \mathrm{~mol}^{-1}$, which corresponds to a pressure of $1 \mathrm{MPa}$, in contrast with the maximum heat of adsorption of methane, which corresponds to a pressure of $30 \mathrm{MPa}$ and is $10.794 \mathrm{~kJ} \mathrm{~mol}^{-1}$; hence, the gas adsorption behavior is classed as physical adsorption because the heat of adsorption is significantly lower than the minimum heat of gas

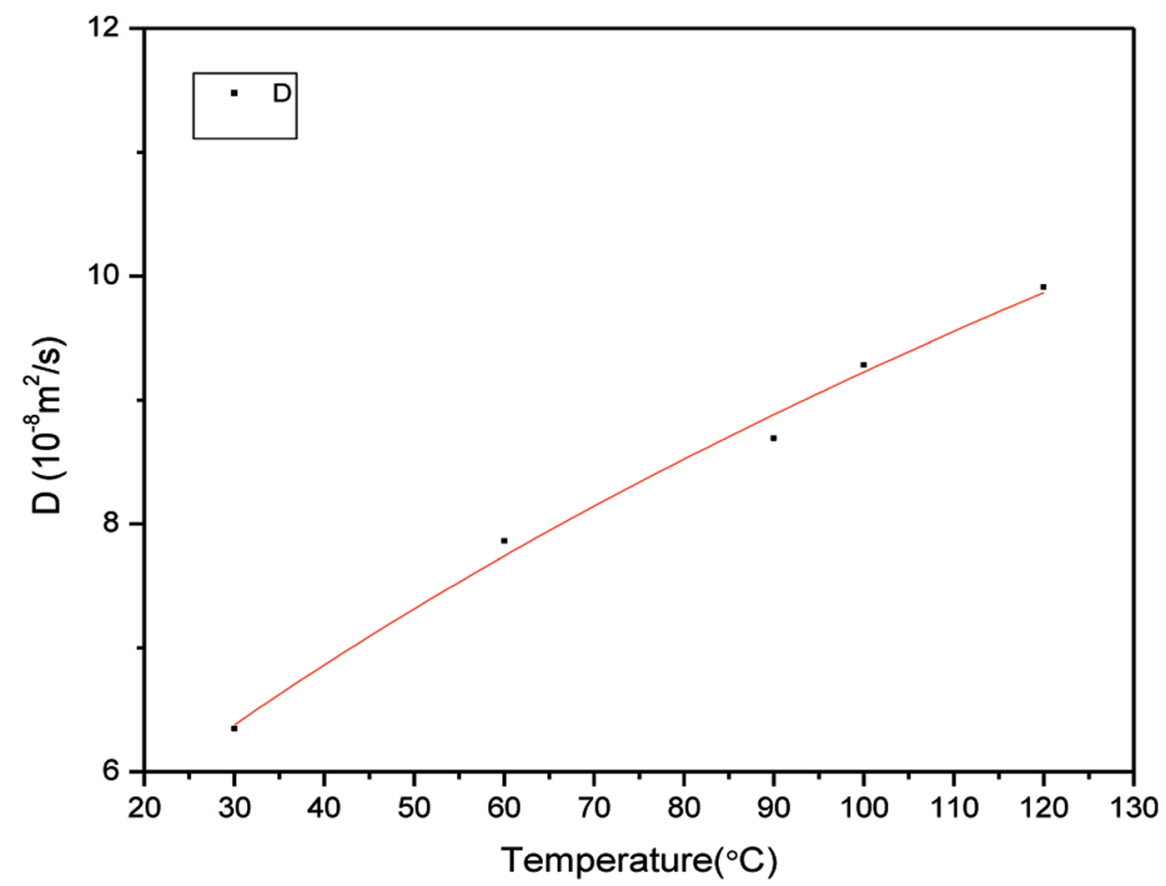

Fig. 8 Relationship between self-diffusion coefficient of methane and temperature in pores with a size of $3 \mathrm{~nm}$ at $21 \mathrm{MPa}$. 


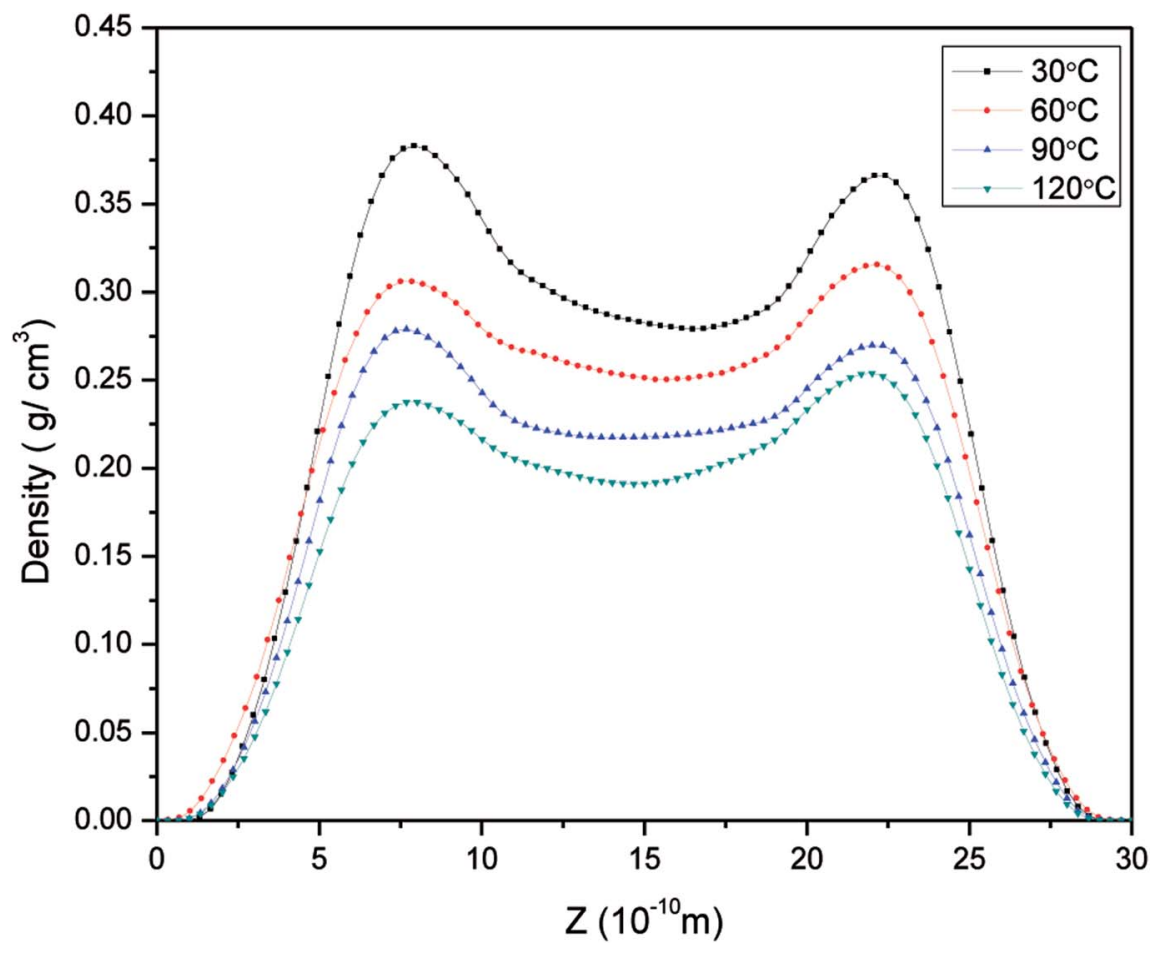

Fig. 9 Density distribution of methane in pores with a size of $3 \mathrm{~nm}$ at $21 \mathrm{MPa}$ at different temperatures.

adsorption for chemisorption. The heat of adsorption of methane at a low pressure is much lower than that of methane at a higher pressure, which indicates that the interaction between methane and quartz is weaker at a lower pressure. The heat of adsorption increases as the pressure increases, for the reason that at a lower pressure a sufficient number of highenergy adsorption sites could support the adsorption of gas molecules on the surface of quartz and produce heat of adsorption, which suggests that this can provide energy to facilitate the molecular motion of methane. However, as the pressure increases more methane molecules are adsorbed and the high-energy adsorption sites are occupied, and the heat of adsorption generated on quartz decreases. The above findings are in accordance with a previous work, which stated that

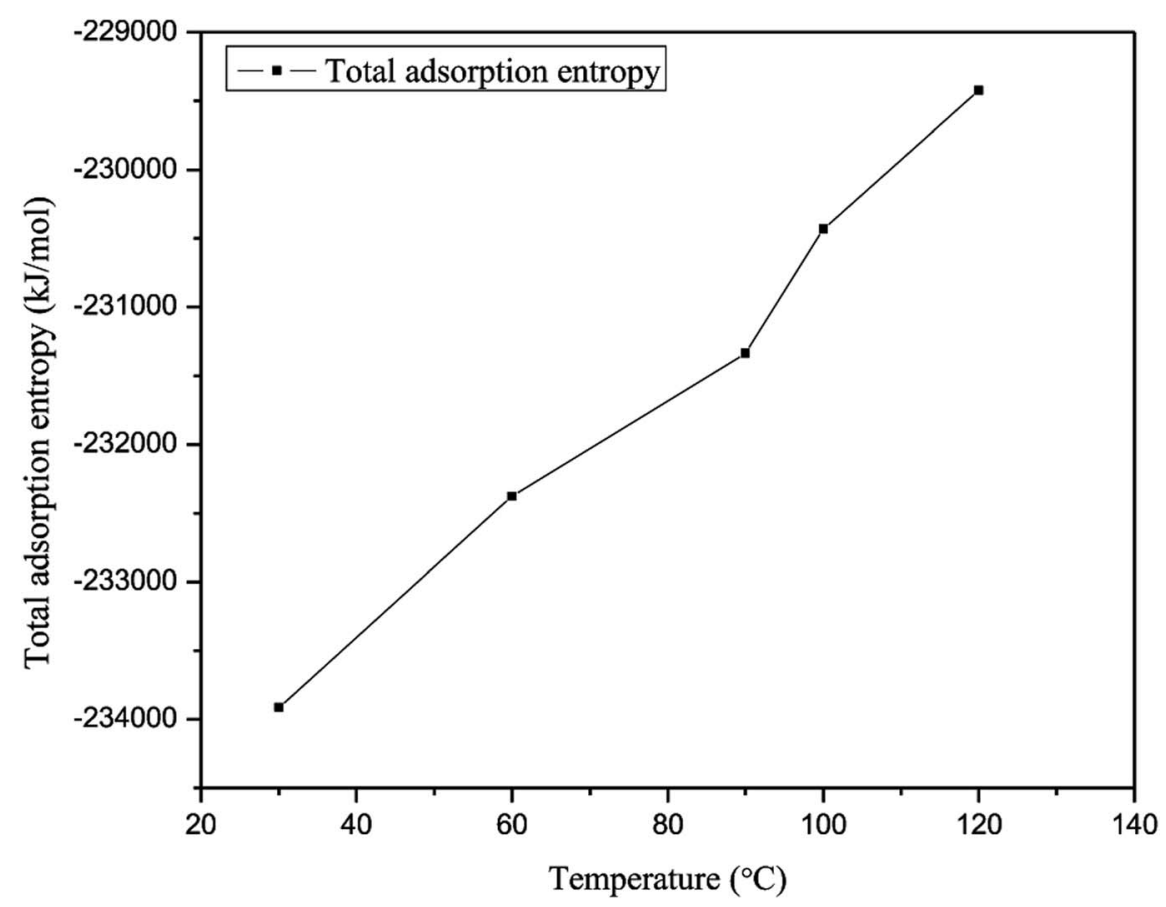

Fig. 10 Relationship between the adsorption entropy and temperature. 

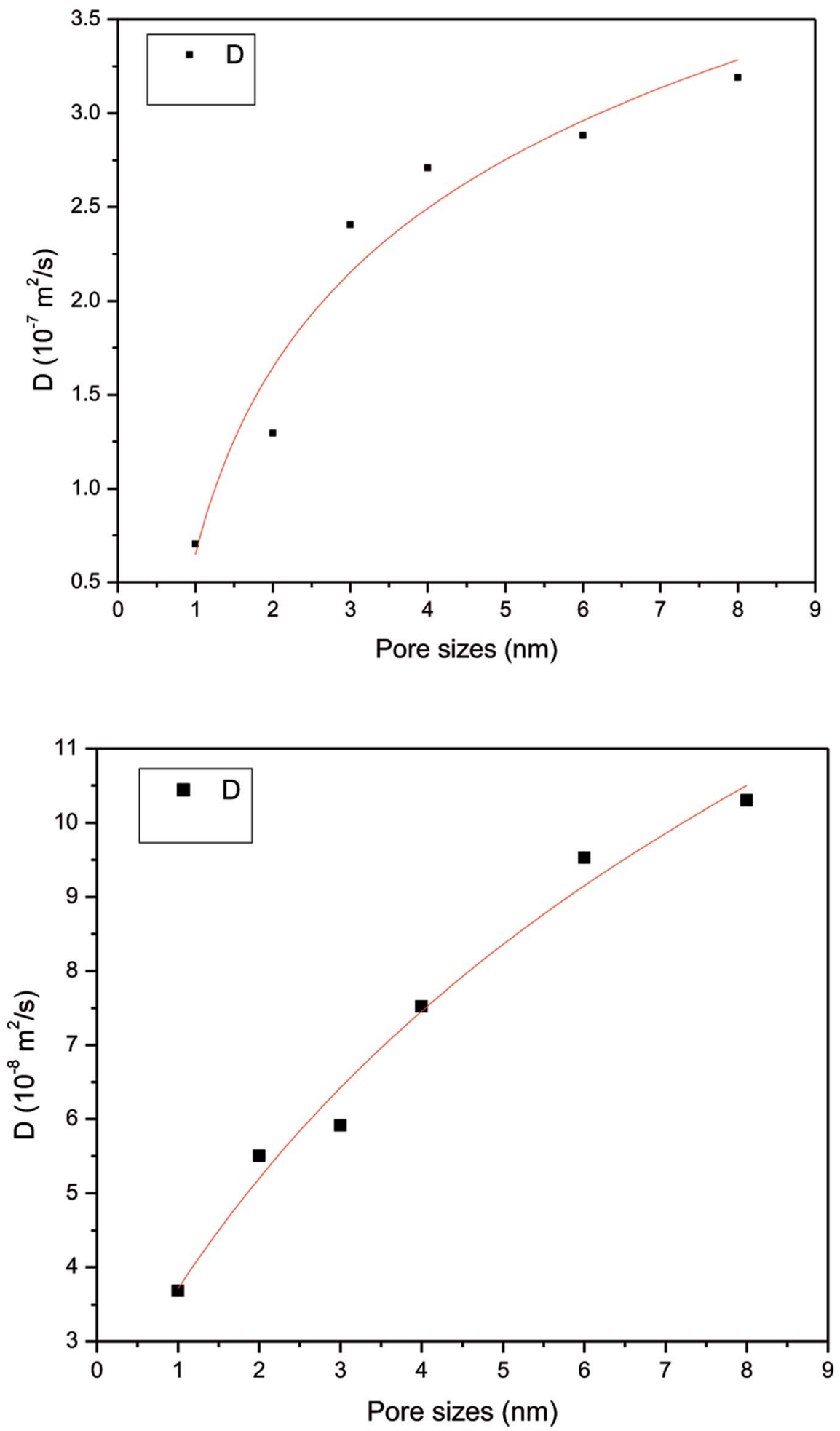

Fig. 11 Self-diffusion coefficient of methane at $5 \mathrm{MPa}$ and $21 \mathrm{MPa}$ for various pore sizes.

methane gas is first adsorbed at higher-energy positions and is then adsorbed at lower-energy positions with an increase in pressure. $^{32}$ Moreover, the interaction forces between methane and quartz increase at a higher pressure, which will constrain the mobility of methane molecules. Therefore, the increase in the adsorption enthalpy is a vital factor when the slit-like pores are filled by methane molecules at a higher pressure.
3.2.2 Impact of temperature. Temperature is a factor that has a positive effect on the diffusion coefficient. According to a previous study, ${ }^{36}$ the diffusion of methane is needed to determine energies of activation, and activation energies remain almost constant within a certain range of temperatures. Therefore, from the relationship between the average isosteric heat of adsorption of methane and the temperature in quartz, 

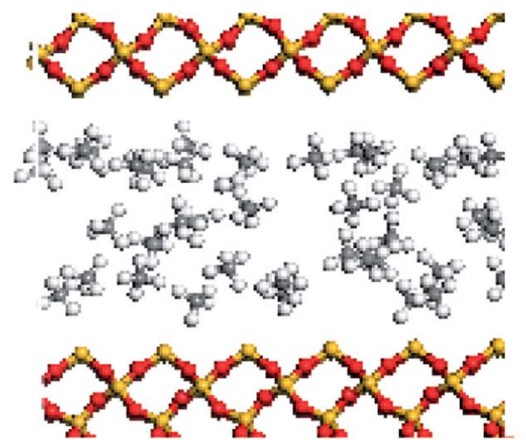

(a)

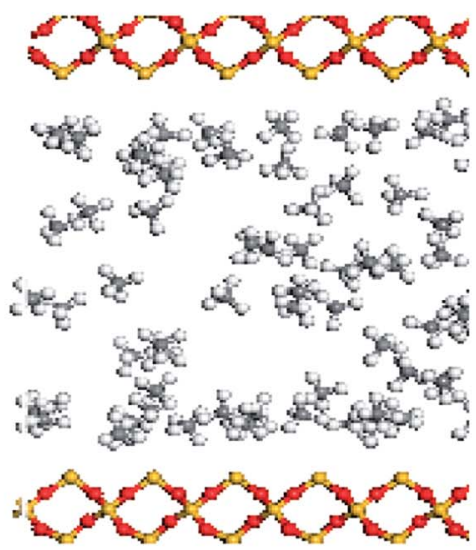

(b)
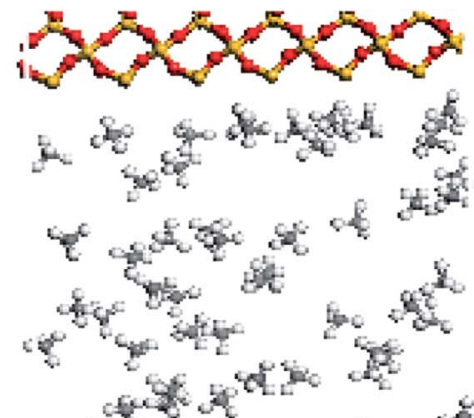

a

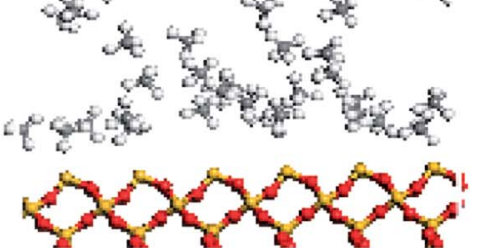

(c)

Fig. 12 Snapshots of methane molecules obtained for a pore size of (a) $10 \AA$, (b) $20 \AA$, and (c) $30 \AA$.

about which more detailed information can be seen in ref. 10, we can draw the conclusion that the diffusion of methane needs a higher isosteric heat of adsorption at a lower temperature, but less isosteric heat of adsorption is required at a higher temperature. Liu et al. (2012) found that the diffusion coefficient of methane in sandstone has a dynamic relationship with temperature and observed that the diffusion of methane in sandstone increases with an increase in temperature on the basis of their experimental measurements. ${ }^{37}$ Moreover, from Fig. 8, we can obtain the result that the molecular transport of methane increases with an increase in temperature, for which the reason may be that the increase in the diffusion coefficient on quartz that is caused by an increase in temperature leads to a rise in kinetic energy in gas molecules. As a result, the mobility of gas molecules quickly increases, which leads to an increase in the diffusion coefficient. Therefore, the results of our

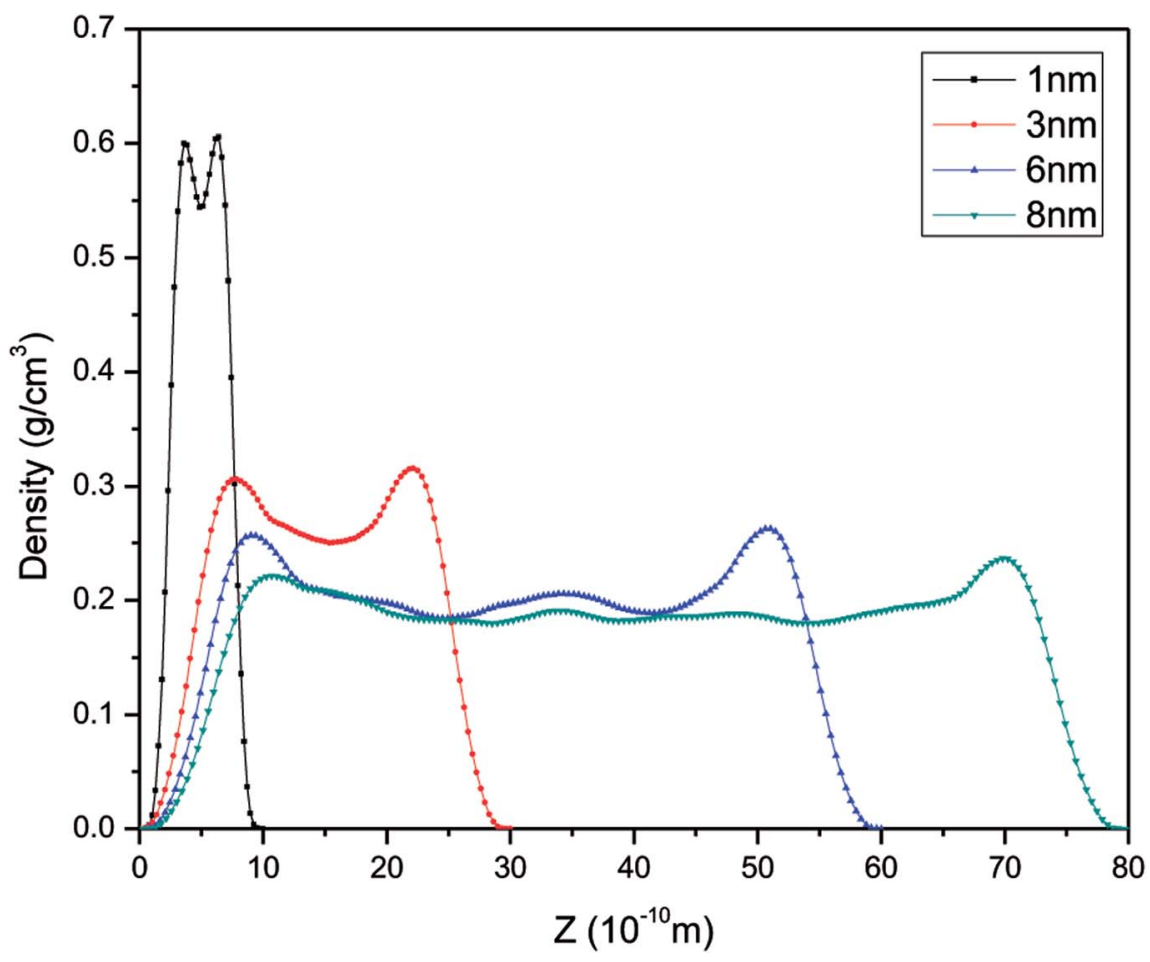

Fig. 13 Density distributions of methane at $21 \mathrm{MPa}$ for various pore sizes. 


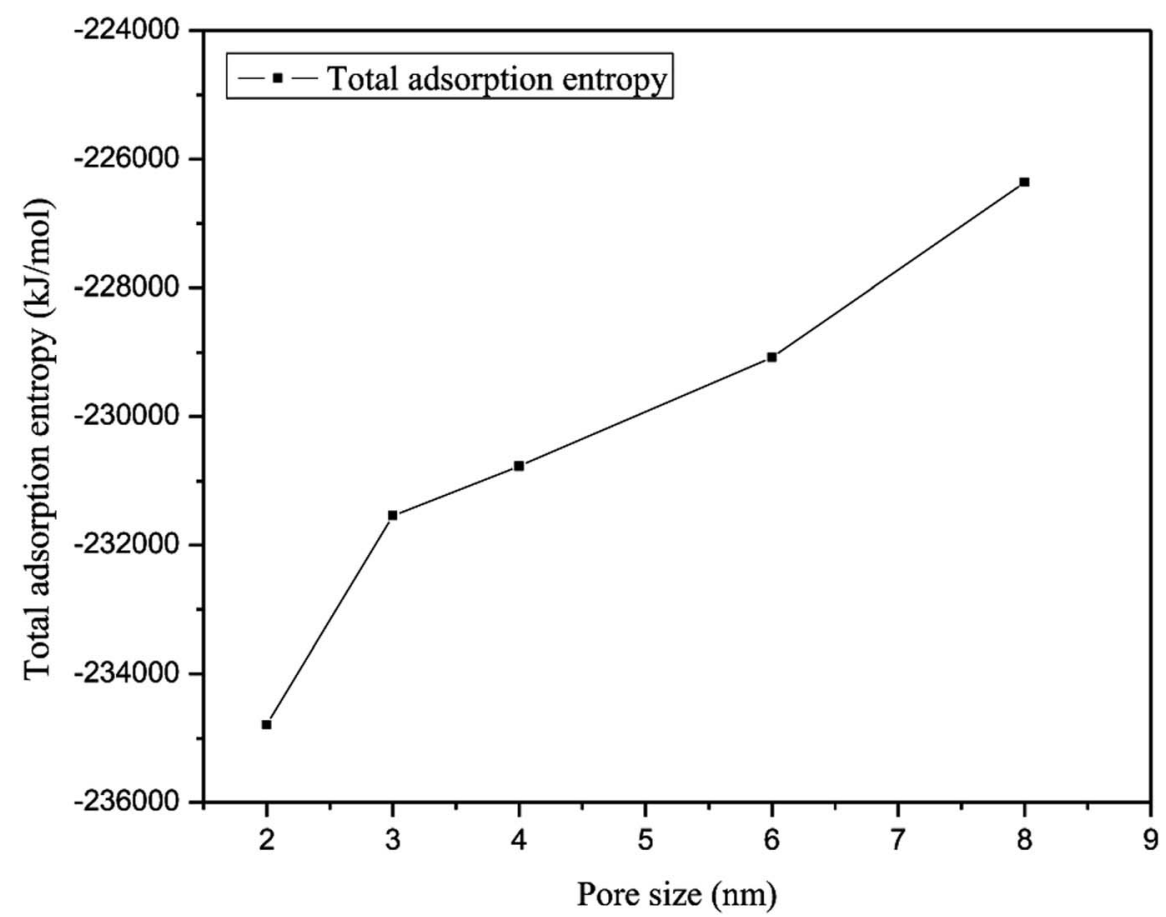

Fig. 14 Relationship between the adsorption entropy and different pore sizes.

simulation, which are related to the relationship between the diffusion coefficient of methane and the temperature in sandstones, have a similar trend to those in previous studies based on experimental measurements. ${ }^{37}$ In addition, we investigated the density profile as a function of temperature to verify the increase in the mobility of gas molecules because of the increase in temperature. From Fig. 9, we indirectly find that an increase in temperature causes a decrease in the adsorbed amount of methane. This finding is in accordance with a previous investigation of the adsorption of $\mathrm{CH}_{4}$ in porous carbon systems. ${ }^{38}$ The figure illustrates that an increase in temperature causes the density of $\mathrm{CH}_{4}$ to decrease. From the density distributions of methane at different temperatures, we can see that the two obvious peaks indicate that methane forms a monolayer at a distance of about $7 \AA$ and $23 \AA$, respectively. Moreover, it can be seen that the density is largely constant in an area close to the centre of the pore. However, there is a decrease in density at locations where a monolayer forms and at the centre of the pore with an increase in temperature. This finding can be explained in that a decrease in the interaction force between gas molecules and the two sides of the pore wall is caused by an increase in temperature, which results in a decrease in the density of methane at different temperatures. In other words, the processes of methane adsorption are equivalent to exothermic processes, which can be found in a previous work that demonstrated the relationship between the isosteric heat of adsorption of methane and the temperature. ${ }^{10}$ The mobility of gas molecules increases, which easily overcomes the force that keeps methane away from the pore walls, and also the capacity for gas adsorption decreases with an increase in temperature. Therefore, the temperature plays a dominant role in increasing the diffusion coefficient of methane molecules.

The adsorption entropy is also an important thermodynamic parameter for the adsorption of gas molecules because it reveals restrictions on the motion of adsorbed gas molecules. ${ }^{39}$ The adsorption entropy of methane was determined to demonstrate the interaction between methane and quartz. Fig. 10 illustrates the curve for the adsorption entropy on slit-like quartz as a function of different temperatures. In this simulation, the adsorption entropy for the adsorption of methane has a minimum value of $-2.34 \times 10^{5} \mathrm{~kJ} \mathrm{~mol}^{-1}$, which corresponds to a temperature of $30{ }^{\circ} \mathrm{C}$, whereas the maximum adsorption entropy of methane, which corresponds to a temperature of $120{ }^{\circ} \mathrm{C}$, is $-2.29 \times 10^{5} \mathrm{~kJ} \mathrm{~mol}^{-1}$. The total adsorption entropy of methane at a high temperature is significantly greater than that of methane at a low temperature, which indicates that the interaction between methane and quartz is weak at a high temperature. The total adsorption entropy increases as the temperature increases, the explanation for which may be that as the temperature increases the motion of gas molecules is more prominent and there is an increase in internal energy because of the increases in potential energy and kinetic energy. Hence, the total increase in entropy with an increase in temperature results in an increase in the mobility of the gas that is due to the reduction in interactions between methane molecules and quartz.

3.2.3 Impact of pore size. It can be seen from Fig. 11 that the diffusion coefficient of methane is between $3.68 \times 10^{-8}$ and $10.3 \times 10^{-8} \mathrm{~m}^{2} \mathrm{~s}^{-1}$ at $21 \mathrm{MPa}$ for different pore sizes and the diffusivity of shale gas is between $6.2 \times 10^{-8}$ and $3.25 \times 10^{-7} \mathrm{~m}$ $\mathrm{s}^{-2}$ at $5 \mathrm{MPa}$ for different pore sizes. From the above 
investigations, the results demonstrate that higher pressures are less beneficial for the transport of methane in quartz than lower pressures. In addition, it can be seen from the two following figures that the diffusion coefficient of shale gas increases with an increase in pore size. Moreover, the investigations found that the diffusivity of methane increases slowly at a higher pressure with an increase in pore size in comparison with that at a lower pressure, and this finding indicates that the

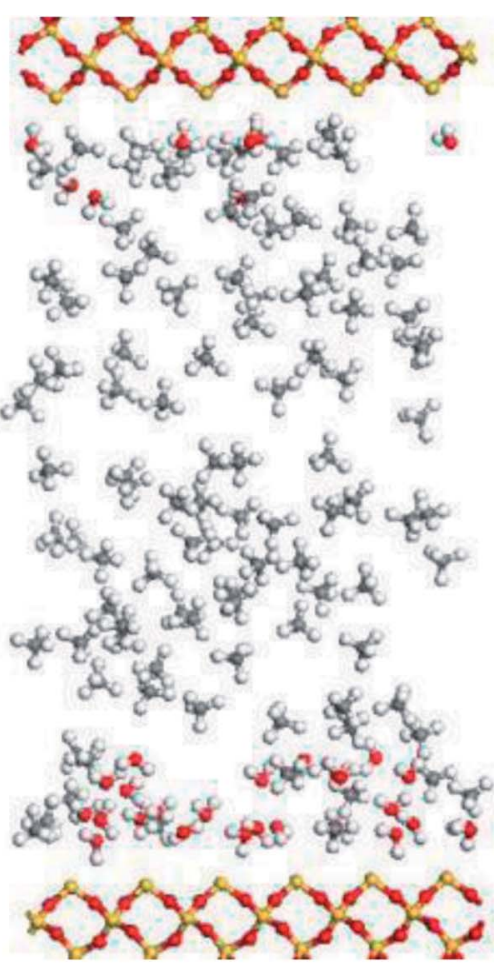

$2 \%$

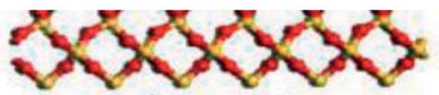

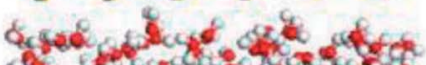

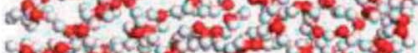

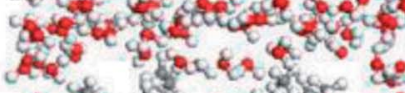

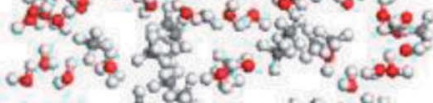

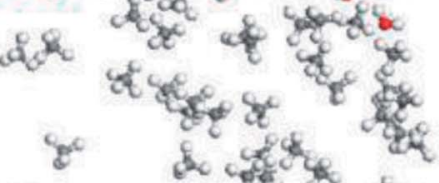

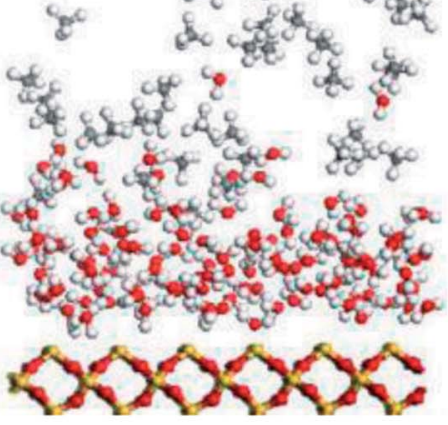

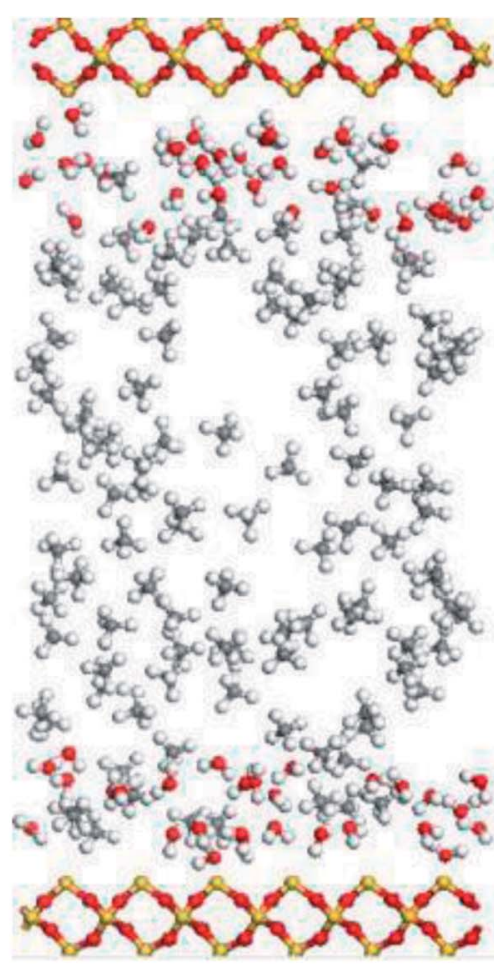

$4 \%$

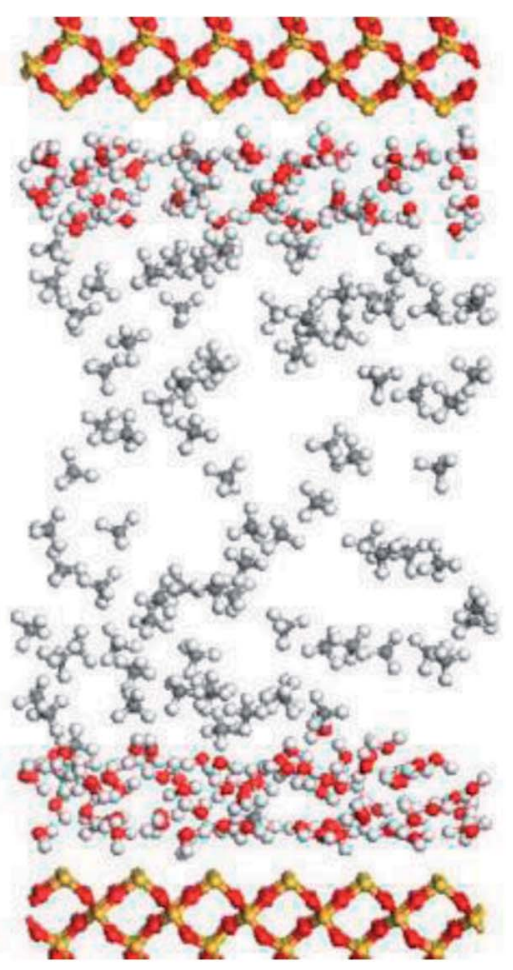

$8 \%$

Fig. 15 Distribution of methane molecules with various water saturations in a $4 \mathrm{~nm}$ pore. 
diffusion ability decreases at a higher pressure. From the snapshots of methane molecules in Fig. 12, an insight into the structure of methane can be obtained. As can be seen, at a pore size of $10 \AA$ methane molecules are tightly packed within the walls because of the limited space, which suggests that the interaction forces between $\mathrm{CH}_{4}$ molecules and quartz are stronger. Moreover, the adsorption of methane on the surface of the walls is dependent on the diffusion coefficient under certain conditions. Therefore, the diffusion coefficient of methane for a pore size of $10 \AA$ is very low, which can be seen in Fig. 11 . However, with an increase in pore size the accumulation of methane molecules on the surfaces of the pore sides is reduced because the strong affinity of the molecules decreases with an increase in pore size of quartz, which is shown in Fig. 12. Even though slow diffusion occurs on the pore surfaces, the gas molecules in the centres of the pores display much faster mass transport owing to the decrease in affinity at the surfaces. Hence, the accumulation of methane molecules at the pore walls decreases and the diffusion of gas molecules in the centers of the pores also accelerates the diffusion of methane on the surface, which causes a general increase in the diffusion coefficient. As a consequence, the general density of methane also decreases with an increase in vacuum strength in this case. These discoveries are in accordance with those of a previous investigation about diffusion in shale gas reservoirs. ${ }^{40}$

In order to study further the mobility of methane molecules in nanopores, we investigated the density distributions of methane at a bulk pressure of $21 \mathrm{MPa}$ for various pore sizes, as can be seen in Fig. 13. First of all, we obtained the result that the density at the pore centre is notably low for different pore sizes and remains almost constant for larger pore sizes. The constant density occurs because in this location methane molecules can be freely transported and the impact of the surface can be ignored. In addition, we can see a decrease in the density of the contact layer with an increase in pore size, which is in accordance with the molecular configuration of methane displayed in Fig. 12. Methane molecules accumulate close to the pore walls and form a molecular layer because of the interaction forces between the molecules and the pore surface. In addition, we determined that the density distribution of methane decreases with an increase in pore size. These findings are in agreement with those of preceding investigations on gas adsorption in inorganic nanopores ${ }^{18}$ and sodium montmorillonite clay hydrates. ${ }^{12}$ Xiong et al. demonstrated that a monolayer forms in micropores and a multilayer forms in macropores by using molecular simulations. ${ }^{10}$ However, this study shows that the monolayer that forms has no relationship with the pore size in this simulation. These results are different from the results of previous works, but both of these also have certain similarities, which may be due to the use of different study methods.

The total adsorption entropy of methane in slit-like quartz as a function of various pore sizes at the same pressure is illustrated in Fig. 14, which shows that an increase in the adsorption entropy of methane is caused by an increase in pore size. As shown in Fig. 14, the total adsorption entropy of $\mathrm{CH}_{4}$ has a minimum value of $-2.35 \times 10^{5} \mathrm{~kJ} \mathrm{~mol}^{-1}$, which corresponds to a nanopore size of $2 \mathrm{~nm}$, whereas the maximum adsorption entropy of methane, which corresponds to a nanopore size of $8 \mathrm{~nm}$, is $-2.263 \times 10^{5} \mathrm{~kJ} \mathrm{~mol}^{-1}$. The total adsorption entropy of methane in small pores is significantly lower than that of methane in large pores, which suggests that the interaction between $\mathrm{CH}_{4}$ molecules and the surface of quartz is strong in large pores. Xiong et al. (2006) observed the influence of

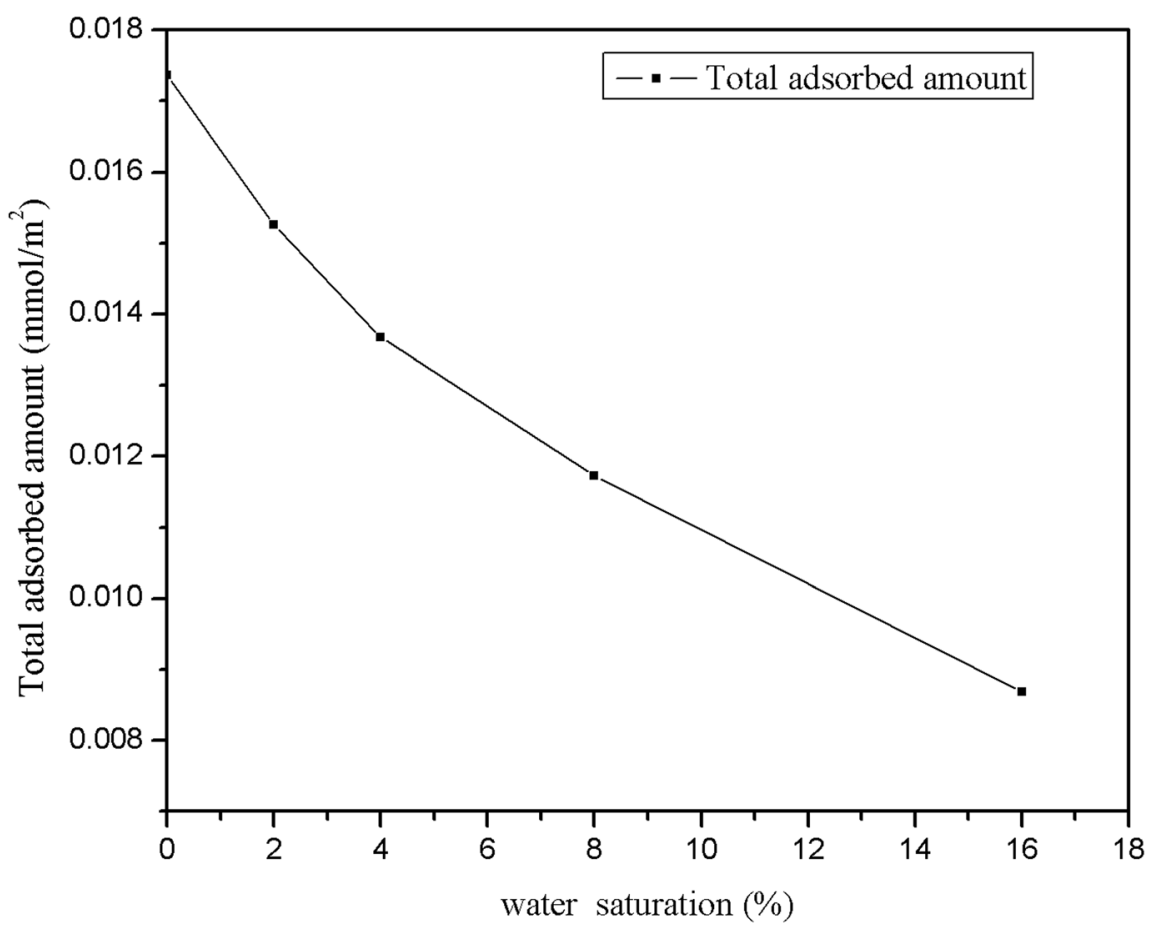

Fig. 16 Relationship between total gas adsorption and water saturation in a $4 \mathrm{~nm}$ pore. 


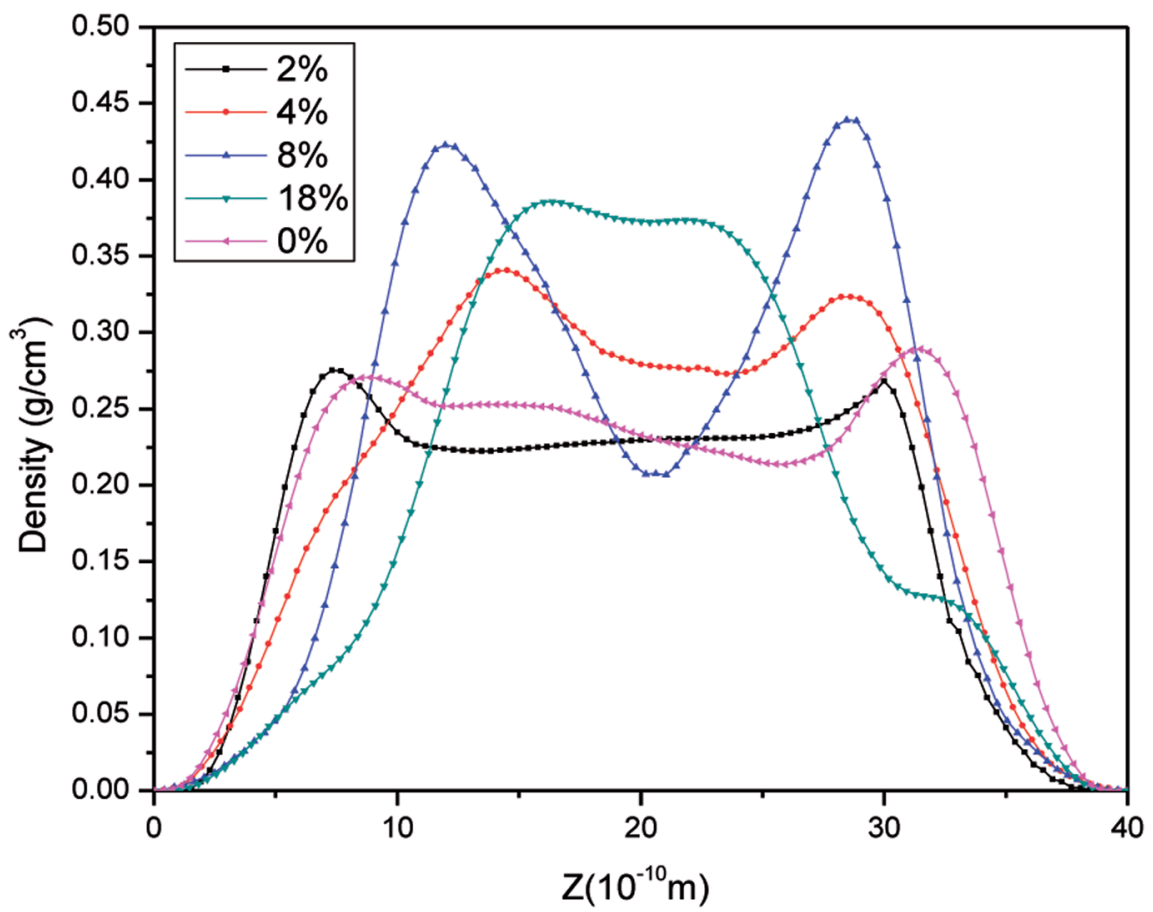

Fig. 17 Methane density distributions at different water contents.

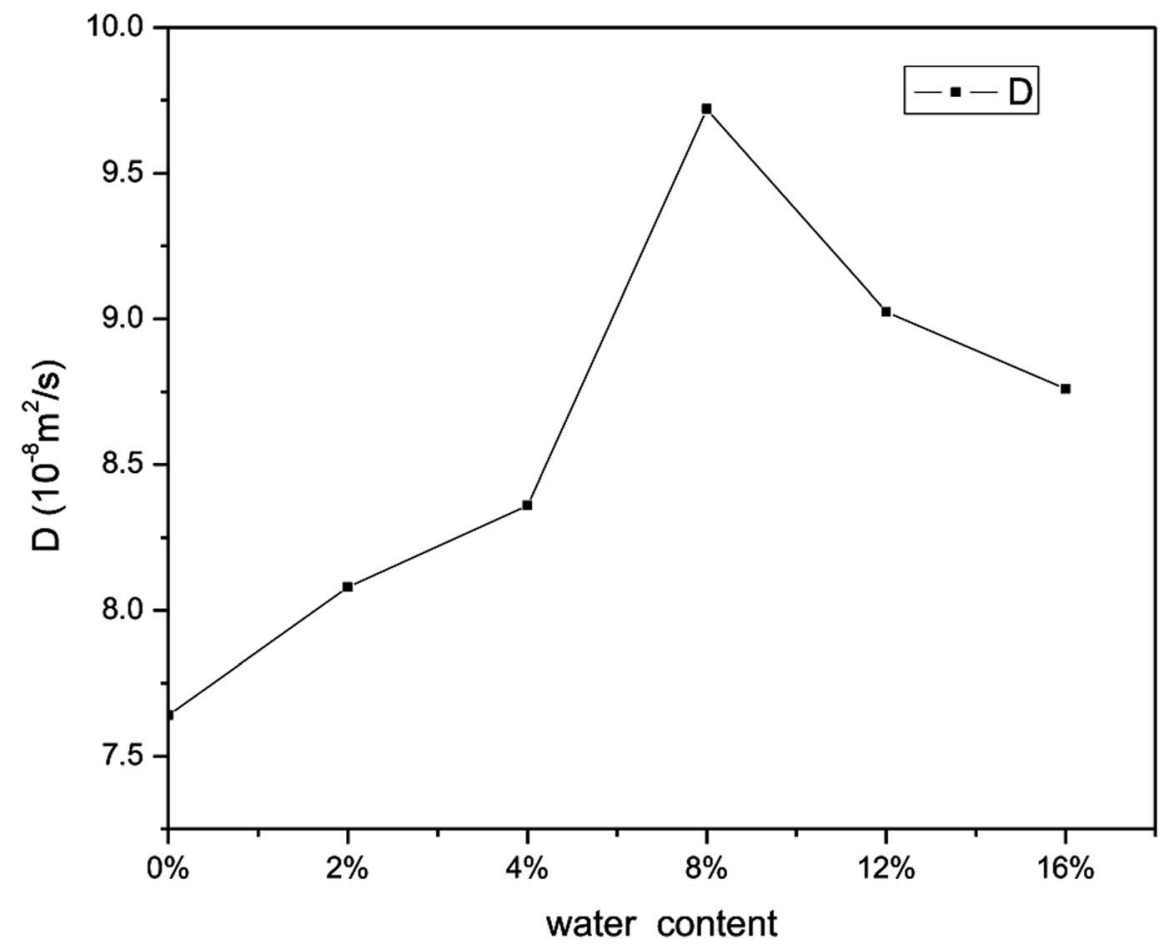

Fig. 18 Self-diffusion coefficient of methane for different water contents at $21 \mathrm{MPa}$.

different pore sizes on the potential energy distribution in quartz and found that gas molecules could be adsorbed at lower-energy positions in micropores; when the pores are macropores, gas molecules could mainly be adsorbed at higherenergy positions and the isosteric heat is higher, which suggests that smaller pores exhibit stronger interactions between methane molecules and quartz. ${ }^{\mathbf{1 0}}$ Therefore, the increase in the total adsorption entropy results in a reduction in interactions between the adsorbent and adsorbate, and hence the motion of gas molecules increases with an increase in pore size. 


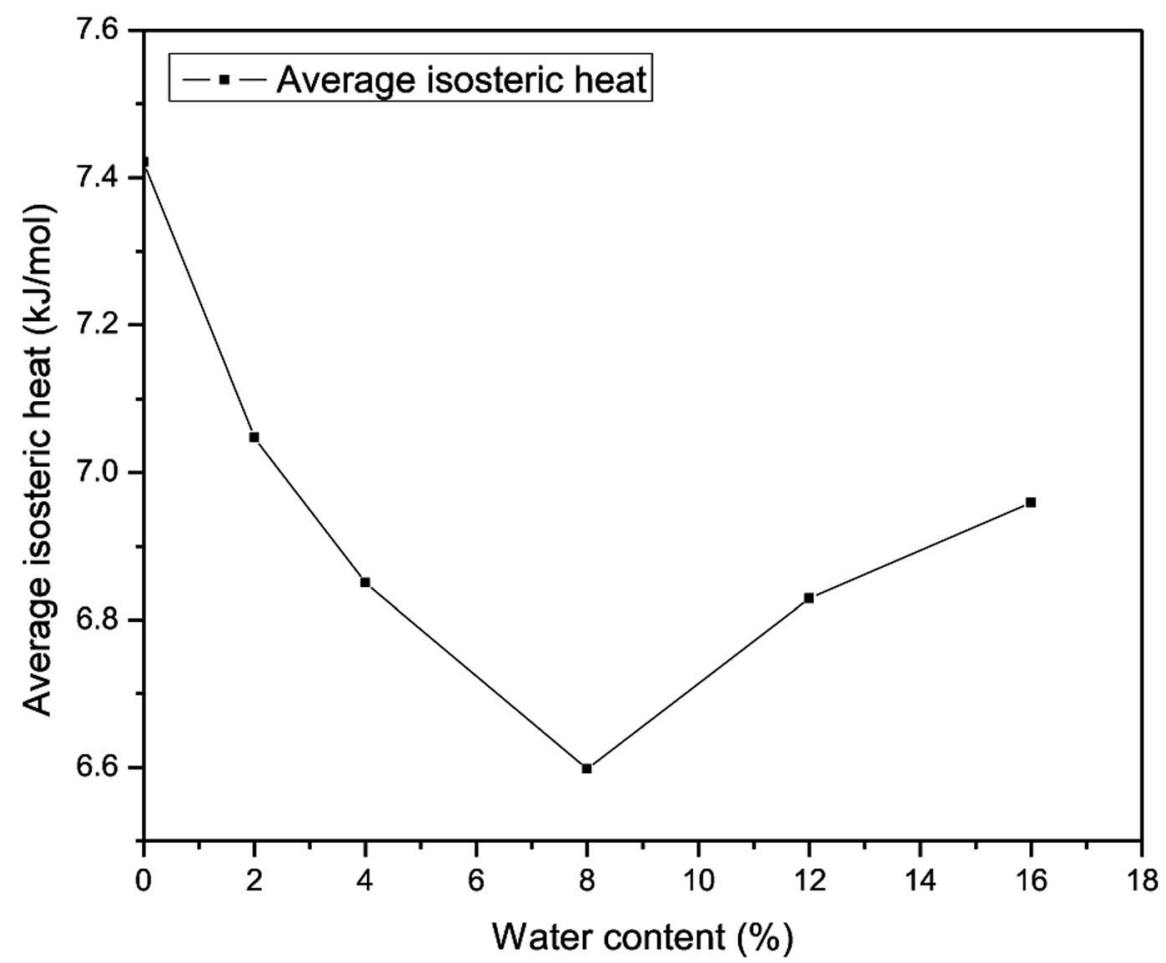

Fig. 19 Correlation between heat of adsorption and water content.

3.2.4 Impact of water content. The effect of the water content on the adsorption behaviour of $\mathrm{CH}_{4}$ in the nanometrescale pore structure of quartz was investigated, which considered the influence of different water saturations $(w \%$, which is the ratio between the total mass of adsorbed water molecules and the mass of the simulation cell). In this study, we performed the simulation work in pores with a size of $4 \mathrm{~nm}$ at a fixed temperature. Snapshots of methane molecules with different water saturations in $4 \mathrm{~nm}$ quartz pores are shown in Fig. 15. As can be seen from this figure, the water molecules are primarily next to the sides of the quartz pore walls and occupy the regions adjoining the quartz pore walls. The water molecules accumulate on the surface of the quartz because there are not only coulombic force interactions but also van der Waals force interactions between the water molecules and the quartz, which leads to the accumulation of water molecules in the area close to the pore walls of the quartz. The above findings inform us that water molecules accumulate and occupy space on the surface of nanometer-scale pores, which results in a decrease in the space available for methane adsorption. Fig. 16 presents the relationship between the total adsorption isotherm and the water content. As can be seen, an increase in the water content causes a decrease in the total adsorbed amount because the water molecules mainly accumulate on the surface of the quartz pore walls, as can be seen in Fig. 15, which brings about the occupation of the space available for the adsorption of methane molecules in quartz. These findings are in accordance with previous reports, which explained that the occupation of the space available for the adsorption of methane molecules in quartz leads to a decline in the methane adsorption capacity from an analysis of the potential energy distribution for the adsorption behavior of methane in quartz pores ${ }^{\mathbf{1 0}}$ and the methane adsorption capacity of organic matter in shale. ${ }^{41}$

The density distributions of methane with different water saturations in pores are displayed in Fig. 17. This shows that the density distribution has a close relationship with the water content. Firstly, the figure shows that the density profiles are almost symmetric about the pore center for different water contents. Secondly, it shows that the density distribution of the gas with a low water content is similar to the density profile without moisture, which indicates that slight water saturation in the pores has a weak influence on the gas distribution. However, with an increase in the water content the area available for the motion of gas molecules in nanopores decreases and the water molecules occupy the surfaces of pores, which leads to an increase in the distance between wall surfaces and gas molecules, as can be seen in Fig. 15, and hence most gas molecules accumulate on the surface of water molecules. In addition, we observe that the density of methane close to the surface of water increases with an increase in the water content. This may be explained by the fact that the speed of accumulation of methane on the surface close to water molecules is higher than that of the dispersion of gas molecules. When the water molecules occupy more space in nanopores, the area available for the motion of gas molecules becomes narrower, which results in an increase in the interaction force between gas molecules. Thus, it can be observed in Fig. 17 that methane becomes tightly packed at a higher water saturation. In summary, the methane density distribution has a close relationship with the moisture content. 
Fig. 18 shows the effect on the diffusion coefficient of methane of different water contents. As can be seen, the diffusion coefficient of methane increases and then decreases with an increase in water saturation. From this figure, it is found that an increase in the water content leads to an increase in the diffusion coefficient of methane when the water content is in the range from 0 to $8 \mathrm{wt} \%$. This is mainly because the surface of the quartz is surrounded by water molecules and the space available for the adsorption of methane decreases with an increase in the number of water molecules. Consequently, the interaction force between the pore walls and methane decreases, which results in an increase in the mobility of methane. This finding is similar to that of a previous report ${ }^{\mathbf{1 2}}$ on hydrated sodium montmorillonite clays. When the water saturation exceeds $8 \mathrm{wt} \%$, the diffusion coefficient of methane displays a decreasing trend. This may be explained by the fact that the water molecules occupy more space in the limited quartz pores with an increase in the water content, and the space available for the motion of methane molecules decreases, which suggests that the distances between methane molecules decrease. As a result, the interaction force between methane molecules makes a great contribution, as the diffusion ability decreases owing to the increase in the interaction force between methane molecules. In summary, the diffusion of methane has a close relationship with the water content.

The average heat of adsorption of methane was investigated to determine the interaction between $\mathrm{CH}_{4}$ molecules and quartz. Fig. 19 presents the average heat of adsorption of methane for different water contents. It demonstrates that the average isosteric heat of adsorption of methane that corresponds to a water content of $8 \%$ has a minimum value of $6.6 \mathrm{~kJ} \mathrm{~mol}^{-1}$, whereas the average heat of adsorption of methane without water reaches a maximum at $7.42 \mathrm{~kJ} \mathrm{~mol}^{-1}$. In addition, it shows that the average heat of adsorption of methane first decreases and then increases with an increase in the water content. The explanation may be that at a lower water content methane molecules could gradually be adsorbed at high-energy sites and produce heat that accelerates the motion of gas molecules. With an increase in the water content, the water molecules will occupy the surface of quartz, which could prevent methane molecules from being adsorbed at high-energy sites, and the isosteric heat generated will decrease, which causes a reduction in the mobility of gas molecules. As the amount of water molecules increases, the simulation system needs an increase in adsorption enthalpy to ensure that methane molecules fill the slit-like pores.

\section{Conclusion}

In this study, environmental factors (such as temperature and pressure) were comprehensively considered in terms of their effect on the diffusion of methane and changes in thermodynamic parameters on quartz from a microscale viewpoint. In this study, GCMC and MD methods were used to study the influences of pressure, temperature, and pore size on the dynamical properties of methane in pores of different diameters in quartz. The following conclusions were reached: (a) The process of methane adsorption comprises a physical adsorption process in which the average isosteric heat and total adsorption entropy are less than $42 \mathrm{~kJ} \mathrm{~mol}^{-1}$ in each adsorption system, and the process of methane absorption is a process that releases heat. Thus, the total energy of the adsorption system exhibits a decreasing trend.

(b) An increase in the pressure causes a reduction in the diffusion coefficient of methane, which is related to a change in the interaction forces between methane and quartz.

(c) The heat of adsorption increases with an increase in pressure, for which the reason may be that $\mathrm{CH}_{4}$ molecules are adsorbed at higher-energy sites and produce isosteric heat at a lower pressure, which increases the mobility of methane molecules. However, the high-energy sites are gradually occupied with an increase in pressure and the heat generated in quartz decreases, which leads to an increase in adsorption enthalpy in the simulation system.

(d) Temperature is a factor that has a positive effect on the diffusion coefficient and changes in entropy, for which the reason may be that an increase in temperature causes increases in the kinetic energy and potential energy of gas molecules, and thus the internal energy increases. Therefore, the adsorption entropy increases with an increase in temperature, which suggests that the reduction in interactions between $\mathrm{CH}_{4}$ molecules and quartz results in an increase in the diffusion coefficient of methane molecules.

(e) With an increase in pore size, methane molecules are gradually adsorbed at higher-energy sites and produce more heat, which results in an increase in the adsorption entropy; moreover, the diffusion ability of methane increases owing to a decrease in interaction forces between quartz and gas molecules.

(f) From microstructural observations, water molecules accumulate on the surface of the quartz wall, which leads to a reduction in the space available for the adsorption of methane, and the methane adsorption capacity is reduced. In addition, the diffusion ability of methane is affected by different water contents, which demonstrates that with an increase in moisture the diffusion coefficient of methane first increases and then decreases, which is related to the distance between gas molecules.

\section{Conflicts of interest}

There are no conflicts to declare.

\section{References}

1 EIA, International Energy Outlook 2017 Overview, U.S. Energy Inf. Adm., 2017, vol. IEO2017, no. 2017, p. 143.

2 J. B. Curtis, Fractured shale-gas systems, Am. Assoc. Pet. Geol. Bull., 2002, 86(11), 1921-1938.

3 L. Ji, T. Zhang, K. L. Milliken, J. Qu and X. Zhang, Experimental investigation of main controls to methane adsorption in clay-rich rocks, Appl. Geochem., 2012, 27(12), 2533-2545. 
4 L. Yingjie, L. Xiaoyuan, W. Yuelong and Y. Qingchun, Effects of composition and pore structure on the reservoir gas capacity of Carboniferous shale from Qaidam Basin, China, Mar. Pet. Geol., 2015, 62, 44-57.

5 F. L. X. Liu, F. L. J. Xiong and F. L. L. Liang, Journal of Natural Gas Science and Engineering Investigation of pore structure and fractal characteristics of organic- rich Yanchang formation shale in central China by nitrogen adsorption/ desorption analysis, J. Nat. Gas Sci. Eng., 2015, 22(April 2011), 62-72.

6 D. J. K. Ross and R. Marc Bustin, The importance of shale composition and pore structure upon gas storage potential of shale gas reservoirs, Mar. Pet. Geol., 2009, 26(6), 916-927.

7 J. Xiong, X. Liu, L. Liang and Q. Zeng, Adsorption of methane in organic-rich shale nanopores: An experimental and molecular simulation study, Fuel, 2017, 200, 299-315.

8 J. Ji, L. ; Ma, X. ; Xia and Y. ; Qiu, relationship between methane adsorption capacity of clay minerals and micropore volume, Earth Science - Journal of China University of Geosciences, 2014, 37(5), 1043-1050.

9 L. Liang, D. Luo, X. Liu and J. Xiong, Experimental study on the wettability and adsorption characteristics of Longmaxi Formation shale in the Sichuan Basin, China, J. Nat. Gas Sci. Eng., 2016, 33, 1107-1118.

10 J. Xiong, K. Liu, X. Liu, L. Liang and Q. Zeng, Molecular simulation of methane adsorption in slit-like quartz pores, RSC Adv., 2016, 6(112), 110808-110819.

11 R. F. Cracknell, D. Nicholson and K. E. Gubbins, Molecular dynamics study of the self-diffusion of supercritical methane in slit-shaped graphitic micropores, J. Chem. Soc., Faraday Trans., 1995, 91(9), 1377.

12 J. O. Titiloye and N. T. Skipper, Molecular dynamics simulation of methane in sodium montmorillonite clay hydrates at elevated pressures and temperatures, Mol. Phys., 2001, 99(10), 899-906.

13 D. Cao and J. Wu, Self-diffusion of methane in single-walled carbon nanotubes at sub- and supercritical conditions, Langmuir, 2004, 20(9), 3759-3765.

14 X. Yang and C. Zhang, Structure and diffusion behavior of dense carbon dioxide fluid in clay-like slit pores by molecular dynamics simulation, Chem. Phys. Lett., 2005, 407(4-6), 427-432.

15 E. Fathi and I. Y. Akkutlu, Nonlinear Sorption Kinetics and Surface Diffusion Effects on Gas Transport in Lowpermeability Formations, SPE Annu. Tech. Conf. Exhib., 2009, (2003), 1-10.

16 S. K. Bhatia and D. Nicholson, Adsorption and diffusion of methane in silica nanopores: A comparison of single-site and five-site models, J. Phys. Chem. C, 2012, 116(3), 23442355.

17 S. Li, K. S. Han, G. Feng, E. W. Hagaman, L. Vlcek and P. T. Cummings, Dynamic and structural properties of room-temperature ionic liquids near silica and carbon surfaces, Langmuir, 2013, 29(31), 9744-9749.

18 A. Sharma, S. Namsani and J. K. Singh, Molecular simulation of shale gas adsorption and diffusion in inorganic nanopores, Mol. Simul., 2015, 41(October), 414-422.
19 P.-H. Huang, S.-C. Hung and M.-Y. Huang, Molecular dynamics investigations of liquid-vapor interaction and adsorption of formaldehyde, oxocarbons, and water in graphitic slit pores, Phys. Chem. Chem. Phys., 2014, 16(29), 15289-15298.

$20 \mathrm{H}$. Sui and J. Yao, Effect of surface chemistry for $\mathrm{CH} 4 / \mathrm{CO} 2$ adsorption in kerogen: A molecular simulation study, $J$. Nat. Gas Sci. Eng., 2016, 31, 738-746.

$21 \mathrm{H}$. Sun, COMPASS: An $a b$ Initio Force-Field Optimized for Condensed-Phase ApplicationssOverview with Details on Alkane and Benzene Compounds, J. Phys. Chem. B, 1998, 5647(98), 7338-7364.

22 H. Sun, P. Ren and J. R. Fried, The COMPASS force field: parameterization and validation for phosphazenes, Comput. Theor. Polym. Sci., 1998, 8(1-2), 229-246.

23 S. Lifson, a. T. Hagler and P. Dauber, Consistent Force Field Studies of Intermolecular Forces in Hydrogen-Bonded Crystals. 1. Carboxylic Acids, Amides and the $\mathrm{C}=\mathrm{O} \cdots \mathrm{H}-$ Hydrogen Bonds, J. Am. Chem. Soc., 1979, 101, 5111-5121.

24 M. Waldman and A. T. Hagler, New combining rules for rare gas van der waals parameters, J. Comput. Chem., 1993, 14(9), 1077-1084.

25 G. Qin and S. He, "Molecular Dynamics Simulation on Modeling Shale Gas Transport and Storage Mechansims in Complex Nano-Pore Structure in Organic Matters," Unconventional Resources Technology Conference (URTEC), 2015.

26 R. Stryjek and J. H. Vera, An improved Peng-Robinson equation of state for pure compounds and mixtures, Can. J. Chem. Eng., 1986, 64(2), 323-333.

27 S. Sircar, Excess properties and thermodynamics of multicomponent gas adsorption, J. Chem. Soc., Faraday Trans. 1, 1985, 81(7), 1527-1540.

28 J. Xiong, X. Liu, L. Liang and Q. Zeng, Adsorption behavior of methane on kaolinite, Ind. Eng. Chem. Res., 2017, 56(21), 6229-6238.

29 H. Sun, H. Zhao, N. Qi and Y. Li, Simulation to Enhance Shale Gas Recovery Using Carbon Dioxide in Silica Nanopores with Different Sizes, Energy Technol., 2017, 250100, 1-8.

30 M. Gasparik, P. Bertier, Y. Gensterblum, A. Ghanizadeh, B. M. Krooss and R. Littke, Geological controls on the methane storage capacity in organic-rich shales, Int. J. Coal Geol., 2014, 123, 34-51.

31 F. Yang, Z. Ning, R. Zhang, H. Zhao and B. M. Krooss, Investigations on the methane sorption capacity of marine shales from Sichuan Basin, China, Int. J. Coal Geol., 2015, 146, 104-117.

32 J. Xiong, X. Liu, L. Liang and Q. Zeng, Adsorption of methane in organic-rich shale nanopores: An experimental and molecular simulation study, Fuel, 2017, 200, 299-315.

33 J. Xiong, X. Liu and L. Liang, Experimental study on the pore structure characteristics of the Upper Ordovician Wufeng Formation shale in the southwest portion of the Sichuan Basin, China, J. Nat. Gas Sci. Eng., 2015, 22, 530-539.

34 M. Helbæk, B. Hafskjold, D. K. Dysthe and G. H. Sørland, Self-Diffusion Coefficients of Methane or Ethane Mixtures 
with Hydrocarbons at High Pressure by NMR, J. Chem. Eng. Data, 1996, 41(3), 598-603.

35 T. Zhang, G. S. Ellis, S. C. Ruppel, K. Milliken and R. Yang, Effect of organic-matter type and thermal maturity on methane adsorption in shale-gas systems, Org. Geochem., 2012, 47, 120-131.

36 P. A. Witherspoon and D. N. Saraf, Diffusion of Methane, Ethane, Propane, and n-Butane in Water from 25 to $43^{\circ}, \mathrm{J}$. Phys. Chem., 1965, 69(11), 3752-3755.

37 G. Liu, Z. Zhao, M. Sun, J. Li, G. Hu and X. Wang, New insights into natural gas diffusion coefficient in rocks, Pet. Explor. Dev., 2012, 39(5), 597-604.

38 K. Mosher, J. He, Y. Liu, E. Rupp and J. Wilcox, Molecular simulation of methane adsorption in micro- and mesoporous carbons with applications to coal and gas shale systems, Int. J. Coal Geol., 2013, 109-110, 36-44.

39 X. Xia, S. Litvinov and M. Muhler, Consistent approach to adsorption thermodynamics on heterogeneous surfaces using different empirical energy distribution models, Langmuir, 2006, 22(19), 8063-8070.

40 Z. Zhai, X. Wang, X. Jin, L. Sun, J. Li and D. Cao, Adsorption and diffusion of shale gas reservoirs in modeled clay minerals at different geological depths, Energy Fuels, 2014, 28(12), 7467-7473.

41 J. Xiong, X. Liu, L. Liang and Q. Zeng, Methane Adsorption on Carbon Models of the Organic Matter of Organic-Rich Shales, Energy Fuels, 2017, 31(2), 1489-1501. 